\title{
FAST AND FRUGAL HEURISTICS: TOOLS OF SOCIAL RATIONALITY
}

\author{
Ralph Hertwig and Stefan M. Herzog \\ University of Basel, Switzerland
}

\begin{abstract}
Homo economicus cannot help but be puzzled by people's baffling array of social behaviors that conflict with economic theory. To accommodate these "deviant" behaviors within the standard view of rationality, defined in terms of probability theory, logic and rational choice theory, economists and psychologists tend to inject some psychology into the rational choice framework. In contrast, we propose to start afresh: We put forth the thesis that humans' social intelligence is not qualitatively different from their nonsocial intelligence, and that important aspects of both kinds of intelligence can be modeled in terms of boundedly rational fast and frugal heuristics. These heuristics can be ecologically and socially rational in that they exploit the structure of physical and social environments as well as evolved capacities to foster performance both in games against nature and in social games.
\end{abstract}

\section{HOMO ECONOMICUS: AN AUTIST?}

In one of his essays on neurological disorders, Oliver Sacks (1995) described his first encounter with Temple Grandin, perhaps the most accomplished and renowned adult with autism. A professor of animal science at Colorado State University and one of the few world experts on the design of livestock handling facilities, she has authored unprecedented inside narratives of child and adult autism (e.g., Grandin \& Barron, 2004). Like other autists, she has little intuitive insight into how people work; "human interactions-social, sexual-she cannot 'get'" (p. 260). Much of the time, she said, she feels like "an anthropologist on Mars" (Sacks, p. 259); a remote observer who examines how this strange species, other people, think and feel. As

Our thanks go to Ulrich Hoffrage for many constructive comments. We also thank Laura Wiles for editing the manuscript.

Ralph Hertwig was supported by Swiss National Science Foundation Grant 100014-118283. Part of this manuscript was written while Ralph Hertwig was visiting the Hebrew University's Center for the Study of Rationality, Jerusalem.

Correspondence concerning this article should be addressed to Ralph Hertwig, Department of Psychology, Missionsstrasse 60/62, CH-4055 Basel, Switzerland. E-mail: ralph.hertwig@unibas.ch. 
Sacks tells us, she tries to understand them by, for instance, building up a vast library of experiences over the years. These experiences are:

like a library of videotapes, which she could play in her mind and inspect at any time-"videos" of how people behaved in different circumstances. She would play these over and over again and learn, by degrees, to correlate what she saw, so that she could then predict how people in similar circumstances might act. [....] In one plant she had designed, she said, there had been repeated breakdowns of the machinery, but these occurred only when a particular man, John, was in the room. She "correlated" these incidents and inferred at last that John must be sabotaging the equipment. "I had to learn to be suspicious, I had to learn it cognitively. I could put two and two together, but I couldn't see the jealous look on his face. (Sacks, 1995, p. 260)

Being a "social detective" (Grandin \& Barron, 2004, p. 31), Grandin worked out that she has no implicit knowledge of social conventions, codes and cultural presuppositions or of strong emotions such as romantic love or jealousy. Lacking this knowledge she has "instead to 'compute' others' intentions and states of mind, to try to make algorithmic, explicit, what for the rest of us is second nature" (Sacks, 1995, p. 270).

Oliver Sacks investigates the complexity of being human, chronicling the lives of people with neurological disorders. Economists, cognitive and social psychologists usually study people who function normally. Nevertheless, there is a hidden bond between the essence of the autistic personality, vividly described by Sacks and Grandin, and the nature of rational models of decision making embraced by many economists and some psychologists. The nature of human rationality becomes "autistic" if we, as do many economic analyses (see Camerer \& Fehr, 2006), equate "rationality" with purely self-regarding preferences, individuals' ability to form, on average, consistent probabilistic beliefs about the state of nature, the effects of their behavior and that of others, and the assumption that individuals' choice of actions best satisfies their preferences given their beliefs.

Just like Grandin, the rational Homo economicus often does not "get" the seemingly strange behavior of normal people. Despite or, perhaps, even because of his unbounded computing capacities in terms of, for instance, Bayesian updating of probabilities and backward induction, Homo economicus is out of tune with us, mere mortals, and cannot predict our seemingly bizarre behaviors: for instance, our ability of valuing fairness over self-interest and of resisting, even punishing unfair offers, instead of always choosing what seems in our best interest; our proclivity to be guided by (social) emotions, obligations, feelings of guilt, and other moral sentiments, and our aptitude for making pragmatic, socially intelligent inferences resulting in seeming violations of norms of rationality. Adding to the picture of an estranged Homo economicus, a small but growing number of neuroscientists and neuroeconomists' investigations have found evidence that it is not the behavior of the hale and hearty but the behavior of patients with damage to specified brain regions that proves consistent with Homo economicus' norms (e.g., Hsu, Bhatt, Adolphs, Tranel, \& Camerer, 2005; Koenigs \& Tranel, 2008; Koenigs et al., 2007). 
To date, many have made the case that Homo economicus, the beacon of rationality, is descriptively wrong. Herbert Simon, one of the most outspoken critics of this "Olympian model" (Simon, 1990a, p. 198) of rationality, argued that real humans "have neither the facts nor the consistent structure of values nor the reasoning power at their disposal that would be required ... to apply" the model's principles (p. 197). Consistent with Simon's critique, two lines of research have dealt a powerful blow to the notion of the rational choice model being a descriptive model of human judgment and choice. The first body of evidence-mostly collected by cognitive and social psychologists-suggests that people often do not succeed in forming rational beliefs about events and people in their environment. The second body of evidence-mostly collected by experimental economists-suggests that people do not always choose what seems to be in their best interest.

Our discussion of human rationality will proceed in four parts. Part I is devoted to the two blows that have demolished the descriptive aspirations of Homo economicus. How advocates of the Olympian model of rationality have responded to them is the topic of Part II. Then, Part III reviews an alternative to the Olympian model of rationality that defines intelligent processes in terms of ecologically rational simple heuristics rather than in terms of logic, probability theory, and rational choice theory. Finally, Part IV will, by way of examples, show how the notion of ecological rationality can be extended to include social rationality, thereby emphasizing the fact that other people often create the most important aspects of a person's environment.

\section{PART I: TWO BLOWS TO HOMO ECONOMICUS: COGNITIVE ILLUSIONS AND OTHER-REGARDING PREFERENCES}

In the early 1970s, Daniel Kahneman and Amos Tversky launched one of the most influential research programs in the social sciences, the heuristics-and-biases program. The program's premise is that people's limited cognitive and reasoning powers necessitate their reliance on heuristics such as the availability, representativeness, and the anchoring-and-adjustment heuristics, "approximate methods" in Simon's (1990b, p. 6) terms. Although these heuristics are "highly economical and usually effective, ... they lead to systematic and predictable errors" (Kahneman, Slovic, \& Tversky, 1982, p. 20; Gilovich, Griffin, \& Kahneman, 2002), variously referred to as biases, fallacies, and cognitive illusions. In contrast to the assumption of most economists, that people form rational expectations, the heuristics-andbiases program has demonstrated that people's probabilistic reasoning appears to be systematically biased and error-prone. Moreover, the program highlighted what it saw as the Janus face of simple heuristics: Although they are key mental tools to navigate the twilight of complexity, probability, and uncertainty in which humans find themselves, recruiting them can exact considerable costs in terms of cognitive illusions.

Viewed as difficult to "debias" (e.g., Fischhoff, 1982), these cognitive illusions have been suspected of exacting substantial economic costs. For instance, many economic decisions such as the optimal allocation of resources involve the process of updating probabilities, which, according to the rationality assumption, people 
do in a Bayesian way. Challenging this premise, many experimenters have concluded that people lack the ability to make Bayesian inferences, even in simple situations involving a binary predictor and criterion: "Man is apparently not a conservative Bayesian; he is not a Bayesian at all" (Kahneman \& Tversky, 1972, p. 450). Even worse, people appear to be unable to adhere to very simple rules of probability such the conjunction rule, according to which the conjoint probability $\mathrm{p}(\mathrm{A} \wedge \mathrm{B})$ cannot exceed $\mathrm{p}(\mathrm{A})$. In light of this finding, Tversky and Kahneman (1983) concluded that "[a] system of judgments that does not obey the conjunction rule cannot be expected to obey more complicated principles that presuppose this rule, such as Bayesian updating, external calibration, and the maximization of expected utility" (p. 313). Still another stock-in-trade example of a cognitive illusion is the overconfidence bias, to which many kinds of real-world economic failures have been attributed. The overconfidence bias describes the tendency to be more confident of one's competence and knowledge than one ought to be. Camerer (1995, p. 594), for instance, suggested that the high failure rate of small businesses may be due to overconfidence, whereas Barber and Odean $(2000,2001)$ argued that overconfidence based on misinterpretation of random sequences of successes leads some investors, typically men, to trade too much on the stock market. ${ }^{1}$

The heuristics-and-biases program has attracted the attention of numerous social scientists, including behavioral economists (e.g., Rabin, 1998; Shiller, 2005), legal scholars (e.g., Sunstein, 2000), marketing researchers (e.g., Bazerman \& Moore, 2008), and medical decision-making researchers (e.g., Chapman \& Elstein, 2000). The program has also made strong inroads into social psychology, beginning with Nisbett and Ross' (1980) classic Human Inference: Strategies and Shortcomings of Social Judgment. Drawing inspiration and concepts from the heuristics-and-biases program, social psychologists have catalogued numerous biases in people's statistical inferences about themselves in relation to others-one domain of social intelligence-such as the false consensus effect, optimistic bias, and the false uniqueness effect, to name just a few (for an encompassing list of these "social biases" and a critical discussion see Krueger \& Funder, 2004).

The heuristics-and-biases program has challenged the premise of the "Olympian model" of economic rationality, according to which individuals are able to form accurate probabilistic beliefs about their world by emphasizing that our limited cognitive machinery is "not built (for whatever reason) to work by the rules of probability" (Gould, 1992, p. 469), and that human beings are a species that is uniformly probability-blind (Piattelli-Palmarini, 1994). This was the first blow dealt to Homo economicus. The second attack was equally devastating, or perhaps even more so, because it moved the focus from the limits in our cognitive machinery to the essence of what is human. If people's preferences are not entirely self-

1. In psychology, the reality of the overconfidence bias is disputed. Several researchers have argued that the bias is an artifact of experimenters' typically nonrepresentative sampling of stimuli (e.g., Gigerenzer, Hoffrage, \& Kleinbölting, 1991; Juslin, Winman, \& Olsson, 2000; see also Dhami, Hertwig, \& Hoffrage, 2004). One problem with naively comparing the overconfidence research in psychology and economics is that quite distinct phenomena have been subsumed under one label. Excessive trading on the stock market (for an overview, see Glaser, Nöth, \& Weber, 2004), for instance, is likely to be quite different in the underlying process and function from miscalibration in one's general knowledge. 
regarding, then the classic economic model simply does not get human behaviornot (only) because it overestimates people's computational capabilities but, more plainly, because it misconstrues the basics of human nature. ${ }^{2}$

Perhaps the most famous social game in which Homo economicus' misconception of human behavior was revealed is the ultimatum game (Güth, Schmittberger, \& Schwarze, 1982). In its simplest form, the ultimatum game involves a single round in which one person, the proposer, suggests splitting a fixed pie (say, $\$ 100$ ). The proposed split represents an ultimatum to the other person, the responder, who must accept or reject it. If the proposed distribution is accepted, it will be implemented. A rejection, however, results in a default payment-typically zero-for each player. Due to the extreme asymmetry in available actions, the equilibrium for this game involves very asymmetric payoffs: If the responder is self-regarding, she will accept any positive payoff in excess of the default value, even an offer of $\$ 1$, because it is better than nothing. Knowing this, a self-regarding proposer will offer just that, $\$ 1$. This prediction hinges on the assumption that the responder is rational and acts in a self-regarding manner, and that the proposer is convinced that the responder is rational and will act in a self-regarding manner. In reality, many responders reject low offers in this game, thus punishing themselves (i.e., forgoing the share of the pie offered to them) but also punishing the responders (i.e., imposing the default payment on them, typically zero). This (anticipated) fact induces many proposers to make equal or relatively equal offers, say $\$ 50-\$ 50$ or $\$ 45-\$ 55$ that will likely be accepted. This convergence toward an equal allocation across proposers and responders appears to be robust across a wide variety of different cultures (e.g., Henrich et al., 2005; Roth, Prasnikar, Okuno-Fujiwara, \& Zamir, 1991). Some researchers have interpreted the pervasiveness of egalitarian outcomes in this game as a sign that people value and enforce a norm of fairness (e.g., Güth \& Tietz, 1990; and see Camerer \& Fehr, 2006; and see Binmore's, 2005, critique of the established interpretation of the ultimatum game).

Ultimatum game behavior is just one of many behaviors that bewilder Homo economicus. A myriad of results observed in social dilemma problems (public good, common pool problems), gift-exchange games, prisoner's dilemma games, trust games, and moonlighting games (see Ortmann \& Hertwig, 2008) indicate that humans are able to demonstrate a baffling array of social behaviors that appear strangely at odds with game-theoretic predictions, and more generally, with the view of humans as exclusively self-regarding utility maximizers.

\section{PART II. HOMO ECONOMICUS: WHAT TO DO WITH THE MISFIT?}

What to do with a model of rational man who lacks social intelligence, and who doesn't quite get how normal people behave? One reaction-not infrequently displayed by economists - is to argue that the contradictory evidence will just not generalize from the laboratory to the real world. The arguments for this assertion include that in most of the experiments, participants were not paid contingent on

2. However, even if people had proved to be behaving in an exclusively other-regarding manner, they still might not have arrived at the rational solution in numerous social games because these games assume cognitive abilities surpassing those of most mere mortals (e.g., backward induction; Nagel, 1995). 
their performance (see Hertwig \& Ortmann, 2001), or not paid enough to motivate them to act in accordance with expected utility theory, laws of probability, and self-regarding preferences (e.g., Harrison, 1994). Outside of the laboratory, so the reasoning goes, market pressures will largely eliminate those who fail to live up to these standards. The University of Chicago economist and Nobel prize laureate George Stigler was a hard-nosed believer in the self-regarding core of human nature when "self-interest and ethical values with wide verbal allegiance are in conflict. Much of the time, most of the time in fact, the self-interest theory ... will win" (1981, p. 176). The behavioral economist Camerer (2003) poked fun at this position: "If I had a dollar for every time an economist claimed that raising the stakes would drive ultimatum behavior toward self-interest, I'd have a private jet on standby all day" (p. 60). Indeed, overall, a significant number of "socially deviant behaviors" of real people have survived such attempts to demonstrate their feebleness relatively unscathed (see Ortmann \& Hertwig, 2008).

\section{SOCIAL PREFERENCE MODELS}

The second reaction to violations of rational choice theory has been to accept the experimental evidence and to modify the theory while retaining the original expected utility maximization scaffolding. These modifications represent, in Selten's (2001) words, a "repair program" that aims for minimal divergence from Homo economicus by inserting emotions, social norms, and forms of social intelligence into the utility function. The most prominent of these revamped utility models, abandoning the assumption of selfishness as the sole driver of human behavior while retaining the rational choice framework, are those of Rabin (1993), Kirchsteiger (1994), Levine (1998), Fehr and Schmidt (1999), Bolton and Ockenfels (2000), Dufwenberg and Kirchsteiger (2004), and Falk and Fischbacher (2006). Fehr and Schmidt, for instance, entered the notion of inequality aversion into the utility function, and assumed that players, disdaining inequity, will reject low offers once the disutility from inequality exceeds the material loss.

How well this and other patching-up of the utility function works is not undisputed - there are those who have criticized some of these social preference models as still debating what is common knowledge in psychology, for instance, the fact that inferred intentions matter to people. Gigerenzer and McElreath (2003) pointed out that Fehr and Schmidt's (1999) and Bolton and Ockenfels' (2000) models assume that intentions of fairness are behaviorally irrelevant, notwithstanding countless studies in psychology demonstrating that even very young children can already distinguish between bad outcomes that were caused intentionally, unintentionally, or because there was no other choice. Indeed, the observation that people reject low offers from humans but are more inclined to accept them from computers flies in the face of the assumption that intentions do not matter (Blount, 1995; Sanfey, Rilling, Aronson, Nystrom, \& Cohen, 2003). Relatedly, Krueger, Massey, and DiDonato (2008) have argued and demonstrated that people, next to their self-interest, are driven by concerns for a positive self-image and the reputation of being a moral person. Adherence to norms can be used to support the latter interests. Because norm adherence is flexible across situations and sometimes only second to self-interest, they doubted whether a utility framework could take these additional variables into account. 
Aside from the question of whether the repair offered by the social preference models works, the general strategy, fixing the rational theory by making as few changes as possible, is no new kid on the block. Its roots date back to Daniel Bernoulli $(1738 / 1954)$, and his solution of the St. Petersburg paradox. In this celebrated challenge to the expected-value calculus, a theory believed to describe the reasoning of the educated homme éclairé, people are not prepared to pay more than a few coins for the right to participate in a lottery that offers an infinitely large gain. To solve this paradox, Bernoulli retained the core of the expected value theory, but suggested that the pleasure or utility of money does not increase linearly with its monetary value, but rather that the increases in utility decline (in modern terms, he assumed diminishing marginal utility). Since Bernoulli instigated the expected utility framework, many violations of its predictions and axioms have been found. In order to explain these "behavioral anomalies," the repair strategy has been habitually called upon. Empirical demonstrations of human behavior in conflict with expected utility theory were explained by adding one or more psychological variables such as emotions (e.g., disappointment and regret) or reference points to the expected utility maximization framework. Examples include cumulative prospect theory (Tversky \& Kahneman, 1992), disappointment theory (e.g., Bell, 1985), regret theory (e.g., Loomes \& Sugden, 1982), and decision affect theory (Mellers, 2000). What these repair theories of risky choice have in common with the revamped utility models for social games is that they all retain the assumption that human behavior can or should ultimately be modeled within the Bernoullian expected utility framework. ${ }^{3}$

\section{FAST AND FRUGAL HEURISTICS}

Beyond disbelief and repair work, there has been a third way of responding to empirical evidence conflicting with Homo economicus: step entirely outside the utility maximization framework, and start afresh on the basis of empirically-rooted knowledge about what the human mind can actually do. Nobel laureate economists Herbert Simon and Reinhard Selten have proposed just such a bold new vision of rationality, namely, in terms of bounded rationality. Intellectually indebted to this notion and its emphasis on the match between mind and environment, the research program on fast and frugal heuristics - as put forward in Gigerenzer, Todd, and the ABC Research Group (1999), Gigerenzer and Selten (2001), Gigerenzer and Engel (2006), and Todd, Gigerenzer, and the ABC Research Group (in press)-has advocated a vision of rationality according to which much of human reasoning and decision making can be modeled by fast and frugal heuristics. ${ }^{4}$ Rather than championing optimization as the hallmark of human rationality, these heuristics obey the bounds of the human mind: They forgo much computation and do not calculate quantitative probabilities and utilities. These heuristics repatriate the debate on human rationality by returning us to the reality of the human mind, and

3. For descriptive models of risky choice that step outside of this framework see, for instance, Brandstätter, Gigerenzer, and Hertwig (2006, 2008), and Busemeyer and Townsend (1993).

4. The research program on fast and frugal heuristics has also been inspired by work in psychology, first and foremost by Payne, Bettman, and Johnson's (1993) metaphor of the "adaptive decision maker." 
trying to answer the question, how do humans with little time and knowledge really behave?

Several authors have argued that there is no way of determining whether a behavioral pattern is, for instance, internally consistent or maximizes utility without referring first to something external to this behavior (e.g., Sen, 1993; Gigerenzer, 1996). Two key external factors are the ecological structures of the environment in which heuristics are employed and the social context of choice such as people's social objectives, values and motivations. The entailed meaning of rationality is thus no longer logical or syntactical but ecological: A heuristic is not per se rational or irrational; rather, its rationality depends on the match between the architecture of the tool and the structure of the environment in which it is employed. That is, the conjecture is not that fast and frugal heuristics are unconditionally successful. Rather, their performance depends on whether, to borrow a notion from Brunswik (1957), environment and cognition have learned to come to terms with each other by mutual adaptation (without implying that all or even the majority of heuristics represent evolutionary adaptations), and whether, to borrow Sperber's (1994) distinction, the heuristic's actual domain possesses the key informational structures of its proper domain. Moreover, rationality is no longer measured exclusively in terms of criteria of consistency (e.g., coherence, transitivity, and accordance with rules of probability) but first and foremost in terms of correspondence criteria (such as speed, frugality, and accuracy; Hammond, 1996).

\section{NORMS OF SOCIAL RATIONALITY: CONTENT- AND CONTEXT-DEPENDENT}

Before we turn to the key concepts of the research program on fast and frugal heuristics in the next section, let us briefly review some of the common and distinct features of the two research programs on heuristics in psychology. The heuristicsand-biases and the fast-and-frugal-heuristics programs share the premise that the rational-choice framework rests on impracticable assumptions about what real people can do. They also agree, in contrast with the social preference models, in not engaging in repair work (with Kahneman \& Tversky's, 1979, prospect theory being a notable exception). Rather, they model the mental tools that the boundedly rational mind recruits in the same terms, simple heuristics. But when it comes to the rationality of these simple heuristics, the two research programs take drastically different views. Specifically, the fast-and-frugal-heuristics program defies a core premise of both the heuristics-and-biases program and the repair tradition. Despite all differences, these latter two espouse formal principles of logic, probability theory, and rational choice theory as the a-priori, content- and context-independent yardsticks of rationality. The fast-and-frugal-heuristics program does not accept the semi-divine status of these standards but asks, when violations occur, what other reasonable concerns may be at play (of course, not excluding the possibility that the observed behavior may indeed be dysfunctional; see, for instance, the aforementioned distinction between a heuristic's proper and actual domain, Sperber, 1994)?

The research programs' different stances regarding norms of rationality has immediate implications. The less than Olympian human mind is not the only reason 
why people's judgments can deviate from the answer that is deemed correct. Even if a problem we face requires merely modest computations, we may seemingly go astray. For illustration, let us return to the simplest law of probability (Tversky \& Kahneman, 1983, p. 294), the conjunction rule. The most famous task designed to study whether people obey this rule is the Linda task. Respondents read a brief personality sketch of a person, Linda. The sketch describes her as an educated, outspoken, social activist. Based on this information, respondents are then asked to rank statements about Linda according to their probability. The crucial ones are "Linda is a bank teller" (T) and "Linda is a bank teller and is active in the feminist movement" (T\&F). In conflict with the conjunction rule, in numerous studies most people ranked Linda to be more likely a bank teller and active in the feminist movement than a bank teller (e.g., Tversky \& Kahneman, 1983). The suggested explanation was that people judge representativeness rather than probability. Indeed, Linda resembles a prototypical feminist bank teller more than she resembles a prototypical bank teller.

Why do people resort to the representativeness heuristic in the Linda problem? Obviously the reason is not that ranking a few statements according to their probability brings our cognitive machinery to the brink of mental exhaustion. The heuristics-and-biases program, building on the recently espoused distinction between two reasoning systems (Kahneman, 2003), argues that the slow reasoning system (System 2) fails to notice and correct the representativeness assessment produced by the fast and automatically operating intuitive system (System 1). Of course, this begs the question of why the reasoning's system fails to detect the "attribute substitution" (probability by representativeness). Because of Inhelder and Piaget (1964), we know that the conjunction rule (or its equivalent, class inclusion) is part of the cognitive repertoire of concrete-operational children as young as eight years. Why does the reasoning system not tap into this repertoire? Is it because the reasoning system's (System 2) ways are effortful and serial, and thus very quickly hampered by our cognitive limits? If so, then even for computationally undemanding tasks such as the conjunction problem, the ultimate explanation for violations would be the limits in our cognitive capacities.

There is, however, a very different path to understanding violations in the Linda problem. It begins with the question: Should we uncritically accept the contentblind conjunction rule as the embodiment of sound reasoning in the Linda task? In doing so, sound reasoning would be reduced to mechanically applying the rule, and nothing else. One need not even read the description of Linda. All that counts are the terms probability and and, each of which-from the point of view of the conjunction rule- has one and only one meaning: mathematical probability and the logical operator $\wedge$, respectively. The Linda problem, however, is presented in natural language terms. Therefore, it comes with the semantic and pragmatic ambiguity of natural language. In the eyes of the linguist Sweetser (1990),

... it is a mistake to analyze natural-language words like and as being identical to entities of the man-made logical terminology which so clearly derives from natural language (rather than the other way around) and so clearly has needs and purposes distinct from those of natural language. (p. 92)

In natural language, terms such as and and probability often have multiple meanings and meanings that are different from mathematical probability and the logi- 
cal and. If, in addition, conversational maxims (Grice, 1989) employed to disambiguate lexical and pragmatic ambiguities suggest that probability does not mean mathematical probability and and does not mean the logical operator, then violations of the conjunctions would be a reflection of sound and intelligent semantic and pragmatic inferences (see Hertwig, Benz, \& Krauss, 2008; Hertwig \& Gigerenzer, 1999; but see also Mellers, Hertwig, \& Kahneman, 2001; Sides, Osherson, Bonini, \& Viale, 2002). On this view, the conjunction fallacy, and possibly several other cognitive illusions (Hilton, 1995) are not due to cognitive limits. They stem from the imposition of normative rules that ignore the uncertainties inherent in language such as polysemy and pragmatic ambiguity. They also follow from a neglect of the content- and context-specific maxims of conversations-embodiment of social rationality-indispensible in helping speakers and hearers to navigate the twilight of linguistic ambiguity.

\section{PART III: BOUNDED RATIONALITY AND ECOLOGICAL RATIONALITY}

People have to solve important and complex problems—such as deciding whether and whom to marry-under conditions of limited time, knowledge, and computational capacity. Consider Charles Darwin's way of making this decision. He methodically listed the pros and cons of marriage (e.g., constant companion, ... who will feel interested in one, object to be beloved and played with-better than a dog anyhow) and bachelorhood (e.g., not forced to visit relatives, and to bend in every trifle) before deciding to marry (Darwin, 1887/1969, pp. 232-233). Despite his readiness to take such a systematic approach to deciding his love life, Darwin could hardly have made this decision according to the classical models of rational choice. As Herbert Simon (1978), in his Nobel Memorial Lecture, stressed:

The classical model calls for knowledge of all the alternatives that are open to choice. It calls for complete knowledge of, or ability to compute, the consequences that will follow on each of the alternatives. It calls for certainty in the decisionmaker's present and future evaluation of these consequences. It calls for the ability to compare consequences, no matter how diverse and heterogeneous, in terms of some consistent measure of utility. (p. 353)

Suppose Darwin had attempted to make his decision in the spirit of the rational choice model. While he searched all alternatives open to choice (marrying or not marrying; if marrying, whom to marry), listing each of the infinite conceivable current and future consequences of each alternative, assigning probabilities to each, gauging his current and anticipating his future evaluation of these consequence (e.g., how important is constant companionship to be now and in the future), and pondering whether the benefits of further search (mates or information about mates) surpass the costs, the prospective wives would all most likely have found somebody else, had children, and died.

What Darwin's dilemma illustrates is that life's important problems cannot necessarily be solved by optimization because the space of possibilities that must be taken into account is often unlimited. Second, even when this space is limited and knowledge is complete, optimization is often impossible to achieve in any real sys- 
tem owing to the computational demands it poses. Even in the well-defined problem space of chess, calculating the optimal solution proves computationally intractable (or NP-hard; Fraenkel \& Lichtenstein, 1981). Third, in many social contexts, specifically, in relationships in which loyalty, dependability, and trust matter, the idea of choosing the alternative with the best-anticipated consequences can violate people's moral sense (Tetlock, 2003). When a man (or woman) proceeds rationally by empirically investigating all potential partners, the possible consequences of living with them, and the probabilities and utilities of each consequence, he (or she) risks moral outrage from those being scrutinized. To conclude, for several important reasons-and not just because of the limitations of our cognitive machinery-optimization is typically beyond our reach.

\section{SATISFICING}

Simon proposed that, because of the above reasons and constraints, human decision-making in the real world exhibits "bounded rationality;" in particular, humans "must use approximate methods to handle most tasks" (Simon, 1990b, p. 6). What are these approximate methods? Their key feature is limited information search. Search for information can refer to search either in memory or in external stores of knowledge such as other people, libraries, and the Internet. Restricting search requires some kind of stopping rule. Simon introduced stopping rules through the concept of aspiration levels and satisficing (e.g., Simon, 1957; see Lewin, Dembo, Festinger, \& Sears, 1944 for an early conceptualization of aspiration levels). Satisficing is a strategy for making a choice from a set of alternatives encountered sequentially when one does not know much about the possibilities that still lie ahead. An alternative is acceptable if there exists a set of criteria that describes minimally satisfactory alternatives, and if the alternative in question meets or exceeds all these criteria. The term satisficing is a blend of satisfying and sufficing, denoting that such strategies generally yield results that are sufficiently good to be satisfied with.

The difference between optimizing and satisficing can be described as such: Optimizing is searching through a haystack to find the sharpest needle in it. In contrast, satisficing is searching the haystack to find a needle that is sharp enough to sew with (March \& Simon, 1958/1993). Or take the suitor, Darwin, again. Once he decided he was willing to tie the knot, there would be no optimal way of deciding when to stop looking for prospective marriage partners. ${ }^{5}$ Satisficing offers a solution to this dilemma. It takes the shortcut of predetermining an (adjustable) aspiration level and ending the search for candidates as soon as one is encountered that exceeds this level (Simon, 1956, 1990b). By the way, Darwin's mate search appears to have been quite constrained. He married Emma Wedgewood, his cousin, with whom he had ten children.

5. One algorithm that is often mentioned in this selection context is the $37 \%$ rule (e.g., Mosteller, 1987). According to this rule, Darwin should look at the first $37 \%$ women (of any population of candidates he faces), letting each one pass, but remembering the highest mate value from that set. From the remaining set, he then should select the first woman with a mate value greater than the previously highest value. This rule finds the highest value more often than any other algorithm, and in this sense, is the optimal solution to the problem. Yet, the rule is not really applicable to human mate choice; for instance, it assumes one-sided rather than mutual search (Todd \& Miller, 1999). 
Originally, Simon proposed the notion of satisficing in the context of the behavior of firms (March \& Simon, 1958/1993; Simon 1945/1997). To date, satisficing strategies have been invoked across myriad domains ranging from the mundane activity of shopping in a supermarket with a zillion alternatives to the behavior of firefighters or emergency rescue teams who make high-stakes decisions under conditions of uncertainty and severe time constraints. Rather than identifying the complete set of alternative courses of action, contrasting them in a process of comparative evaluation, they seem to pick one possible action in their race against the clock. They run through it in a mental simulation. If it works "well enough"that is, if the outcomes reach a predetermined goal or exceed a predetermined aspiration level for success - they implement it without considering other options (Klein, 1998).

\section{FAST AND FRUGAL HEURISTICS AND THEIR ECOLOGICAL RATIONALITY ${ }^{6}$}

Satisficing strategies have typically been invoked in the sequential search through options (e.g., apartments, cars, computers, courses of action, mates) that unfolds across time. In contrast, fast and frugal heuristics have typically been proposed to model the cognitive processes underlying choices between simultaneously available options. In this context, search does not refer to a hunt for options, but to a hunt for information-in the form of cues, features, consequences, etc.- -about the present options. For illustration, consider a voter who searches in memory for reasons to vote for one of two candidates in an election, say, the Democratic or Republican primaries in the U.S. in 2008. Let us assume that the concern of our voter, John Doe, is to predict who will be the better (i.e., more electable) candidate to go up against the other party's candidate in the general election. For example, should John Doe "bet" on, say, John McCain or Mike Huckabee (if Doe votes in the Republican primaries), or should he bet on, say, Hilary Clinton or Dennis Kucinich (if he votes in the Democratic primaries). Put differently, the voter's task is to predict which alternative, $a$ or $b$, has the higher value on a quantitative criterion (here, number of popular votes in the general election), where $a$ and $b$ are elements of a set of $N$ alternatives (which can be actions, objects, events, people). This prediction can be based on $M$ binary cues $(1,2, \ldots, i, \ldots, M)$, where the cue values 1 and 0 indicate higher and lower values on the criterion. To predict which of the two candidates will get more votes, John can search for information about, for example: Who has the higher approval ratings among independent voters? Who has the more competitive position on important issues such as the economy, health care and war? But what kind of information will he search for?

The Recognition Heuristic. Perhaps the simplest hypothesis about how John Doe searches for cues and, on their basis, derives a prediction is the recognition heuris-

6. Let us emphasize that we cannot do justice to the many experimental, simulation, and analytical results that have been gathered in the past years. Rather than systematically reviewing this body of work, we focus on the underlying ideas, give illustrative examples, and provide numerous references (for comprehensive overviews, see Gigerenzer et al., 1999; Gigerenzer \& Engel, 2006; Gigerenzer \& Selten, 2001; Hertwig \& Hoffrage, in press; and Todd et al., in press). 
tic (Goldstein \& Gigerenzer, 2002). For two-alternative prediction tasks it can be stated as follows:

If one of two objects is recognized and the other is not, then infer that the recognized object has the higher value with respect to the criterion.

According to this heuristic, if John had not even heard of one of the two candidates (say, Kucinich) but had heard of the other (Clinton), he would infer that the recognized candidate is the more competitive one (and guess, if he had heard of neither). Such recognition knowledge (i.e., knowledge of the previously experienced or believed to be previously experienced) is cognitively inexpensive. During retrieval of a memory record, it arrives automatically and instantaneously on the mental stage, thus ready to enter inferential processes when other knowledge still awaits retrieval (Pachur \& Hertwig, 2006). The recognition heuristic is assumed to be a noncompensatory strategy; that is, as long as one object is recognized and the other is not, search is terminated and no other probabilistic knowledge will be retrieved. ${ }^{7}$

The recognition heuristic works by turning partial ignorance into predictive success. Had John heard of both Kucinich and Clinton, he would not have been able to use the recognition heuristic. For the heuristic to be successful, a person's ignorance needs to be systematic rather than random, thus yielding a correlation-in either direction-between recognition and the criterion (for simplicity, the above formulation of the heuristic assumes a positive correlation). Such substantial correlations exist in competitive situations, including the excellence of colleges (e.g., Hertwig \& Todd, 2003), the quality of athletes (e.g., Pachur \& Biele, 2007; Serwe \& Frings, 2006), and the size of cities (e.g., Goldstein \& Gigerenzer, 2002; Hertwig, Herzog, Schooler, \& Reimer, 2008).

How can one learn the association between recognition and a criterion when the criterion is not accessible, for instance, because it lies in the future? Goldstein and Gigerenzer (2002) proposed that there are mediators in the environment that both reflect (but do not reveal) the criterion and are accessible to decision makers' senses. For example, one may have no direct information about the electability of a politician. However, her competitiveness may be reflected by how often her name is mentioned in the newspaper (ecological correlation). Because the newspaper is accessible, it can operate as a mediator. The frequency of mention, in turn, is correlated with how likely someone is to recognize the politician's name (surrogate correlation). In other words, the more often the name occurs in the newspaper, the more likely it is that a person will recognize the name. Finally, how well a proxy a person's recognition knowledge reflects the criterion is captured in the recognition validity $\alpha$, which is the proportion of times a recognized object has a higher criterion value than an unrecognized object in a reference class, such as politicians competing in an election:

$$
\alpha=R /(R+W),
$$

7. The assumption that recognition is used in a noncompensatory way has been vigorously debated (e.g., Bröder \& Eichler, 2006; Newell \& Fernandez, 2006; Oppenheimer, 2003; Pohl, 2006; Richter \& Späth, 2006; but see also Pachur \& Hertwig, 2006, and Pachur, Bröder, \& Marewski, 2008). 
where $R$ is the number of correct (right) inferences the recognition heuristic would achieve, computed across all pairs in which one object is recognized, and the other is not, and $W$ is the number of incorrect (wrong) inferences.

The recognition heuristic exploits this chain of correlation between the criterion, the mediator, and the mind. It empowers John Doe to make inferences about a candidate's chance of winning the election, depending on as little as name recognition (or lack thereof). How good are such inferences? Scheibehenne and Bröder (2007), for instance, analyzed the extent to which the outcomes of matches in the 2005 Wimbledon Gentlemen's Singles tennis competition could be predicted by mere player name recognition. Amateur tennis players and laypeople indicated players' names they recognized, and predicted match outcomes. Predictions based on recognition rankings aggregated over all participants correctly predicted $70 \%$ of all matches. These recognition predictions were equal to or better than predictions based on official ATP rankings and the seedings provided by Wimbledon experts; only online betting odds led to more accurate forecasts. Beyond sports and politics, consumer decision-making is very likely influenced by name recognition-at least, judging from the many billions of dollars that companies invest to shape our recognition knowledge (e.g., Goldstein, 2007; Hoyer \& Brown, 1990; see Pachur, Todd, Gigerenzer, Schooler, \& Goldstein, in press, for a general review of studies of the recognition heuristic).

The Fluency Heuristic. Heuristics are by nature not all-purpose inferential tools. John Doe, for instance, would not be able to take advantage of the recognition heuristic if he recognized the names of the two remaining candidates in the primaries. What else could he do? There are a number of alternatives, ranging from strategies that invest very little cognitive effort to strategies that aim to retrieve additional knowledge. Another very frugal heuristic is the fluency heuristic (Schooler \& Hertwig, 2005; Hertwig, Herzog, et al., 2008). Like the recognition heuristic, it operates on the basis of mnemonic information that is relatively effortlessly at hand, namely, retrieval fluency of the memory records from long-term memory. More specifically:

If two objects, $a$ and $b$, are recognized, and one of two objects is more fluently retrieved then infer that this object has the higher value with respect to the criterion. ${ }^{8}$

Like the recognition heuristic, the fluency heuristic is useful whenever there is a substantial correlation-in either direction-between a criterion and recognition, and by extension, retrieval fluency of the recognized names. Like recognition proper, retrieval fluency can carry ecologically valid information about quantitative dimensions in the world (see the ecological analyses conducted in Hertwig, Herzog, et al., 2008). For illustration, in the Republican primaries in 2008, John Doe may have recognized the name John McCain much more swiftly than the name Mike Huckabee, thus judging the former to be more electable in the U.S.

8. Hertwig, Herzog et al. (2008) operationalized retrieval fluency in terms of latency of recognition. The larger the differences in fluency between two options, the better people detect them and the more they rely on them. 
general election. This difference in fluency would reflect tangible differences in actual environmental frequencies, as suggested by the ACT-R framework (Schooler \& Hertwig, 2005). For instance, for the period, starting January 1, 2000 until March 2008, the name "John McCain" appeared a total of 5,993 times in the archives of the New York Times (a mediator), whereas "Mike Huckabee" appeared merely 650 times. As Hertwig et al. demonstrated, such differences in environmental exposure can encapsulate predictive power, and the fluency heuristic is a simple mental tool that exploits it.

The Take-The-Best Heuristic. Still another hypothesis of how people make inferences when they recognize both objects is the take-the-best heuristic (Gigerenzer \& Goldstein, 1996). Like the recognition and fluency heuristics, it embodies onereason decision-making insofar as it rests its decision on just one probabilistic cue; unlike in the case of the other two heuristics, this deciding cue, however, can be different across inferences. Take-the-best uses a measure of cue goodness, called validity, to order cues and consists of three building blocks: a search rule, a stopping rule, and a decision rule. The heuristic proceeds as follows:

Search rule. Search through cues in order of their validity. Look up the cue values of the cue with the highest validity first.

Stopping rule. If one object has a positive cue value (1) and the other does not ( 0 or unknown), then stop search and proceed to the next step. Otherwise exclude this cue and search the next cue. If no more cues are found, guess.

One-reason decision-making. Predict that the object with the positive cue value (1) has the higher value on the criterion.

The validity of a cue $i$ is defined as $v_{i}=R_{i} / P_{i}$, where $R_{i}$ equals the number of correct predictions by cue $i$, and $P_{i}$ equals the number of pairs where the value of the cue $i$ differ between objects. ${ }^{9}$ In John Doe's' task of predicting the more electable candidate, for example, he would start by looking up the most valid cue for predicting the candidates' number of popular votes in the general election, and see whether the two candidates differ with respect to that cue. This cue could be, "who has the higher approval ratings among independent voters?" (see Hoffrage, Hertwig, \& Gigerenzer, 2000, for a version of the take-the-best heuristic employing continuous cues). If indeed candidates differed on this cue, John would stop searching and choose accordingly; if not, he would look up the next valid cue and go through the same process until he could make a prediction or eventually would guess. Take-the-best enables frugality by basing a decision on the first discriminating cue rather than looking up all the available cues, and it renders fast decisions possible by avoiding integration of information. Note that for the take-the-best heuristic to be used it does not need accurate validities-any order will do. But to make accurate inferences, a good cue ordering is necessary. Cue validities, however, do not

9. Validity does not guarantee the "best" ordering of cues; it ignores dependencies between cues, and despite (or because of) this produces reasonably robust orders. Given that the problem of ordering cues is computationally intractable, however, it would be unrealistic to assume that minds search for the best order. Fortunately, even if people do not manage to order cues exactly according to their validities but deviate slightly from that, performance does not suffer dramatically (Martignon \& Hoffrage, 2002). 
need to be learned individually. ${ }^{10}$ Validities based on cue validities or other criteria can also be acquired through evolutionary learning or social learning (Gigerenzer, Hoffrage, \& Goldstein, 2008) — an issue to which we return below.

Information search in the real world comes at a cost (e.g., time, opportunity costs). Previous research on adaptive decision-making emphasizes that ignoring information, as take-the-best does, is necessary because of such costs, producing an accuracy-effort trade-off (Payne et al., 1993). This, however, is only half of the story. The other part is that even if the information came at no cost in an uncertain world, cognitive processes should still ignore a portion of it because less effort need not entail less accuracy. On the contrary, simple strategies can often be more accurate than complex strategies (e.g., Dawes, 1979). For instance, the take-thebest heuristic proved to be not only more frugal but also more accurate than multiple regression in prediction. Czerlinski, Gigerenzer, and Goldstein (1999; see also Gigerenzer \& Goldstein, 1996; Martignon \& Hoffrage, 2002) used 20 real-world datasets from a range of domains, including biology, economics, and sociology, to test take-the-best's accuracy, relative to tallying and multiple regression. The datasets were repeatedly split in two random halves and the parameters of each model (weights, validities, directions of the cues) were estimated on one half of the dataset. The parameter estimates were then used to predict for each strategy the paired comparisons on the other half of the dataset for each repetition. With $68 \%$ accuracy, regression was outperformed by take-the-best $(71 \%)$. In a related analysis, Gigerenzer and Brighton (2009) showed that take-the-best is often more accurate and frugal than complex algorithms developed in cognitive science and machine learning (e.g., neural networks, exemplar models, and decision tree induction algorithms). In many real-word situations, the intuitively compelling trade-off between accuracy and effort disappears, and cognition-to the extent it can be described in terms of fast and frugal heuristics-appears to have been evolved to take advantage of this fact.

Fast and frugal heuristics have been proposed across a wide range of tasks such as estimation (Hertwig, Hoffrage, \& Martignon, 1999), classification (Berretty, Todd, \& Martignon, 1999), preferential choice (Brandstätter et al., 2006, 2008), and resource allocation (Hertwig, Davis, \& Sulloway, 2002). In addition, fast and frugal heuristics have been suggested and analyzed in a range of applied contexts such as legal decision-making (Dhami, 2003), geographic profiling (Snook, Taylor, \& Bennel, 2004; Snook, Zito, Bennell, \& Taylor, 2005), medical decision-making (Fischer et al., 2002), and dietary decision-making (Scheibehenne, Miesler, \& Todd, 2007). Moreover, numerous studies have investigated the extent to which models of fast and frugal heuristics accurately describe people's choices and decisions, and the underlying cognitive processes (for reviews of some portions of these studies, see Bröder, in press; Gigerenzer, Dieckmann, \& Gaissmaier, in press; Pachur, Todd, et al., in press).

10. But even individual learning need not be prohibitively complex. Katsikopoulos, Schooler, and Hertwig (2009) demonstrated that the take-the-best heuristic can reach competitively high accuracy, relative to other models of inference, based on minute learning sets (i.e., very few objects from which directionality of cues and cue order are abstracted). 


\section{FAST AND FRUGAL HEURISTICS: WHY DO THEY WORK?}

Accurately solving complex real-world problems demands ostensibly complex computations and, by extension, extensive cognitive resources. This link is explicitly or implicitly assumed in many theories of cognitive processes and visions of rationality (see Hertwig \& Todd, 2003). The surprising accuracy of fast and frugal heuristics, relative to more complex models of choice and decision making, poses a challenge to the conviction that a complex world requires complex means to deal with it successfully. But what is the key to the heuristics' success? There is no single attribute that explains their success; rather it stems from a number of properties that in combination give rise to their success. In what follows, we briefly review these properties (in doing so, we draw on Gigerenzer, 2004).

Exploitation of Evolved Capacities. Heuristics can be exploitation devices, taking advantage of evolved cognitive capacities of the human mind. Those capacities, in turn, can be complex. Consider, for instance, the recognition and the fluency heuristics. Both use the mind's capacity for recognition (faces, voices, or names) and for ecologically smart forgetting (Schooler \& Hertwig, 2005). The latter describes the fact that human memory uses the recency, frequency, and spacing with which information has been needed in the past to estimate how likely that information is to be needed now. Because processing unneeded information is cognitively costly, a memory system able to set aside little needed information by forgetting is better off (Anderson \& Lebiere, 1998). Systematic (rather than random) forgetting in turn fosters the use of the recognition heuristic because it needs partial ignorance. If a person recognizes too few or too many objects, recognition will be uninformative because it will rarely discriminate between objects. Relatedly, the fluency heuristic feeds on retrieval speed and can do so more easily if there are large detectable differences in fluency between objects (Hertwig, Herzog et al., 2008). Schooler and Hertwig (2005) showed that forgetting makes recognition more informative and keeps restoring differences in retrieval speed, thus boosting the performance of the recognition and fluency heuristics, respectively.

Take-the-best and satisficing strategies take advantage of recall memory, including the ability to retrieve cues and cue values when making inferences, and past experiences when determining aspiration levels. The simple tit-for-tat strategy (Rapoport \& Chammah, 1965) rests on the evolved capacity for reciprocal altruism, enabling the social exchange of favors and goods among unrelated conspecifics (Trivers, 1971). Reciprocal altruism in turn requires a suite of cognitive abilities including the ability to detect and punish cheaters, and recall reputation (Stevens \& Hauser, 2004). Clearly, without exploiting evolved capacities heuristics could not get away with their simplicity. However, they are not simply free riders. Heuristics enable the evolved capacities to be applied to domains other than those in which they evolved (Sperber, 1994). In this sense, heuristics can be seen as one mechanism that renders exaptations possible, thus giving rise to the unrivaled flexibility of the human mind (Gould \& Vrba, 1982).

Problem-Specificity. Cognitive faculties such as deductive reasoning, memory and numerical abilities are assumed to treat any content identically, that is, in a domaingeneral way. Numbers are numbers, no matter what their referents are. Heuristics, in contrast, are not domain-general-they solve particular problems. Mate choice strategies feed on different contents (e.g., cues indicative of mates' attractiveness 
such as symmetry, hip-to-waist ratio, monetary resources, character; for a review see e.g., Miller \& Todd, 1998) than, say, food choice strategies (using cues indicative of the nutritional values, taste and safety of food; e.g., Scheibehenne et al., 2007). Although the way to a man's heart is said to be through his stomach, the attractiveness of food and of mates are not the same thing. The existence of contentspecific heuristics points to an intricate division of mental labor, and suggests a modular organization of the human mind (adaptive tool box; Gigerenzer \& Todd, 1999; Todd, Hertwig, \& Hoffrage, 2005). The fact that heuristics are not generalpurpose tools, however, does not mean that each heuristic needs to be invented from scratch, nor that they lack any family resemblance across domains. One way to think about the construction of heuristics is that a few building blocks sampled from a limited set of building blocks-including aspiration levels, ordered search, one-reason stopping rule, emotions, and social norms-are combined, yielding new heuristics to deal with novel tasks. This explains why similarly constructed heuristics such as the take-the-best heuristic and the priority heuristic can account for dissimilar tasks (here inferences and preferences; Brandstätter et al., 2006; Gigerenzer \& Goldstein, 1996).

Ecological Rationality. The fact that heuristics are domain-specific and problemspecific means that their rationality is not logical (domain-general) but ecological. As pointed out earlier, this is one of the key differences between the fast and frugal heuristics, and the heuristics proposed within the heuristics-and-biases research program. Fast and frugal heuristics can be highly adapted to the structures of one environment, and be mismatched to the structures of other environments. Consequently, they exhibit ecological rationality in one domain but not in others. For illustration, consider the recognition and fluency heuristics. They perform well in environments in which there is a strong correlation between recognition and the target criterion. Yet, there are environments in which recognition is intentionally manipulated thus reducing its ecological validity. For instance, the political candidate who raises most money and spends it on ads need not be the most qualified one, nor need the most advertised product be the best one (Goldstein, 2007).

From an ecological rationality perspective it is straightforward to study the adaptation of mental strategies to real-world environments (rather than to compare strategies to domain-general norms), and to measure their performance against a criterion that exists in the environment (see Hammond, 1996, for the distinction between internal coherence vs. external correspondence criteria). Ecological rationality has been one of the important properties of boundedly rational cognition. Simon (1990b) used the analogy of a pair of scissors to emphasize how cognition and environment work in tandem: "Human rational behavior . . . is shaped by a scissors whose blades are the structure of task environments and the computational capabilities of the actor" (p. 7). Just as by only looking at a single blade one cannot fathom how scissors cut, one cannot fully understand how the human mind works by only looking at the heuristic and ignoring its informational ecology.

The study of ecological rationality analyzes which heuristics match with which environmental structures. Its tools are mathematical analysis and computer simulation, and its goal is to describe the statistical or informational properties of the environment in which a given heuristic performs well or fails. The take-the-best heuristic, for instance, will perform well in any environment in which the weights of the cues (corresponding to the order of the cues in take-the-best) decrease ex- 
ponentially, such as $1 / 2,1 / 4,1 / 8$ and so on. In such a noncompensatory information environment, no linear model, including multiple regression, can outperform take-the-best. One can easily comprehend this rule: The sum of all cue weights to the right of a cue can never be larger than this cue's weight. Yet if the distribution of cue validities is equal rather than skewed, a unit-weight model is more accurate than take-the-best (Martignon \& Hoffrage, 2002). Hogarth and Karelaia (2006) conducted another ecological analysis by exhaustively analyzing pair-comparison tasks with 3-5 dichotomous cues and a criterion value that is a linear function of the cue values (plus an error term). They categorized environments according to their relationships between cue weights and were able to distinguish those in which take-the-best outperformed a unit-weight model (Dawes, 1979), and those in which the unit-weight model performed better (see also Hogarth \& Karelaia, 2007).

Robustness. Humans and other animals need to predict the future rather than merely postdict the past. To do this successfully, the organisms need to use strategies that, above all, successfully predict the future, but do not necessarily best explain the past (Gigerenzer, 2008). Strategies that best explain the past are often not those that best predict the future. Robustness is the ability of a strategy to extract relevant information from the past, and to disregard irrelevant information, which will not generalize to the future. Fitting, in contrast, refers to the ability to explain or describe the past (i.e., data that are already known). An excellent fit can be indicative of overfitting; that is, lack of robustness (Mitchell, 1997; Myung, 2000; Roberts \& Pashler, 2000). A strategy is said to overfit relative to another strategy if it is more accurate in fitting known data (hindsight) but less accurate in predicting new data (foresight). One can intuitively understand overfitting from the fact that patterns in past experience can be divided into two: one part that is relevant for the future; and another that is irrelevant and thus represents noise. Everything else being equal, the more difficult a criterion is to predict (that is, the higher its uncertainty), the more noise exists in past information and needs to be ignored. An adaptive cognitive system that operates in an uncertain world thus needs to ignore part of the information. Robustness can be enhanced by ignoring information and by evolved capacities such as forgetting. The art is to ignore the right information. Heuristics embodying simplicity such as one-reason decision-making have a good chance of focusing on the information that generalizes because they are-due to their simplicity-more "immune" to noise. They are less likely to be "fooled by randomness," seeing "faces in the clouds" where there is in fact no pattern. Complex strategies, in contrast, are more prone to overfitting due to their greater flexibility in fitting data, and by extension, noise.

Let us sum up our discussion so far. The research program on fast and frugal heuristics further develops Simon's $(1956,1990 \mathrm{~b})$ notion of bounded rationality by stressing the ecological intelligence of heuristics. It has proposed models of heuristics across a wide range of tasks and domains. A model of a heuristic encompasses search, stopping and decision rules and aims to describe the actual process-not merely the outcome - of decision making. By taking advantage of evolved cognitive capacities, the heuristics can afford to be computationally simple and informationally frugal. By taking advantage of environmental structures, they can achieve as high or even higher accuracy than much more complex models. Due to their simplicity and frugality they are less likely to fall prey to the risk of overfitting, 
relative to complex models. With the framework of fast and frugal heuristics in place, we can now show by means of examples how it can be extended to encompass social rationality.

\section{PART IV. SOCIAL RATIONALITY: SOCIAL HEURISTICS THAT MAKE US SMART}

No other animal's toolbox of cognitive strategies includes as many social heuristics as that of humans. Social heuristics have a wide realm of applications and are used, as proposed by Hertwig \& Hoffrage (in press), in two broad domains: social games and games against nature. Social games refer to situations involving social exchanges, in which other people create the most important aspects of an agent's reactive environment (Byrne \& Whiten, 1988, p. 5). Social heuristics can enable the protagonists in these interactions to make adaptive decisions regarding, for instance, the allocation of tangible and intangible resources, the choice of allies and mates, and the deduction of others' intentions-to name but a few of those decisions involving others. Games against nature refer to situations in which one person needs to predict, infer or outwit nature in order to achieve her ends (e.g., predicting the weather to inform the decision when to sow). The person's outcome is determined jointly by her decision(s) and by the state of nature. A person can engage in games against nature using purely nonsocial information, but can also call upon social information (e.g., what most other people are doing or what the most successful people are doing), thus possibly fostering performance.

We argue that people's decision-making in games against nature and social games can be modeled in terms of fast and frugal heuristics. In doing so, we suggest that the cognitive processes constituting humans' social intelligence are not necessarily qualitatively different from the processes underlying nonsocial intelligence. This thesis conflicts with a frequently made claim according to which social environments are qualitatively different, that is, more complex, than nonsocial worlds. Because of the social world's higher order of complexity, so the argument continues, social and nonsocial intelligence must be distinct. Specifically, the social world has been characterized as more complex, unpredictable, or challenging than nonsocial ones (e.g., Byrne \& Whiten, 1988), and the key objects of the social world, people, have been described as unavoidably complex as targets of cognition (Fiske \& Taylor, 1984, p. 18). Humphrey (1976/1988, p. 19; Sterelny, 2003), for instance, argued that social systems have given rise to "calculating beings," who "must be able to calculate the consequences of their own behaviour, to calculate the likely behaviour of others, to calculate the balance of advantage and loss." He concluded that "here at last the intellectual faculties required are of the highest order" (p. 19). Similarly, the neuroscientists Seymour and Dolan (2008) argued:

Choice in social interaction harbors a level of complexity that makes it unique among natural decision-making problems, because outcome probabilities depend on the unobservable internal state of the other individual, which incorporates their motives (intentions). Because most interactions are repeated, optimal learning requires subjects to generate a model of another individual's behavior, and their model of our behavior, and so on. These iteratively nested levels of complex- 
ity render many social decision-making problems computationally intractable. (p. 667)

In our view, the argument that complex social systems create complex intellectual operations represents another incarnation of the aforementioned deeply entrenched intuition harbored by many scholars of rationality: The more complex a problem, the more complex the cognitive machinery of a successful problem solver needs to be (see Hertwig \& Todd, 2003). The world's complexity thus licenses, in fact even calls for, models of unbounded rationality. One of the problems with this argument is that when one goes beyond its intuitive appeal, it raises more questions than it offers answers (Gigerenzer, 1997). Does complexity refer to the complexity of an environment per se (whatever that is) or to the complexity that an organism is built to take into account? Primates, for instance, exploit individual variations among their conspecifics, but not those among plants, predators, and prey (Kummer, Daston, Gigerenzer, \& Silk, 1997). Is a nonsocial world in which our ancestors faced unpredictable natural hazards such as droughts, famines, floods, lighting, fires, earthquakes, tornadoes, and an endless variety of unknown diseases really less complex than the social world? Or could it be that we project our contemporary view of nature, tamed by ecology, medicine and science, into a past in which people faced far more risks than anybody alive today (Gardner, 2008; Gigerenzer, 1997)?

For the sake of the argument, let us assume that the social world is indeed more demanding and less predictable than nonsocial environments. But would social intelligence therefore require more complex cognition? This view overlooks the importance of robustness. If social environments were indeed more complex, intractable and less predictable than nonsocial environments, successful prediction would call for robust, and thus simple strategies, which successfully generalize to the unknown by ignoring irrelevant information. In addition, the multitude of goals and criteria in social environments renders optimization out of reach, probably even more so than in nonsocial environments. Social environments are notorious for their multitude of conflicting criteria and goals, including speed, accuracy, loyalty, accountability, transparency, trust, dependability, autonomy, honor, pride, face-saving, consent, equity, equality, and self-interest. Optimization, in contrast, requires a single criterion to be maximized. One cannot maximize several criteria simultaneously, unless one combines them by, say, a linear function (but then one needs a justifiable rationale for how to weigh those criteria).

To summarize, boundedly rational heuristics that enable people to make good decisions under the constraints of limited time, information, and computational resources are as important in social as in nonsocial environments, if not even more important. Even if social environments were perceived to be more complex, this complexity does not necessarily demand complex strategies. The same selective forces that are likely to favor the evolution of simple strategies in nonsocial environments such as the need for generalizable (robust), informationally modest (frugal) and fast solutions are also likely to be at work in social environments (Todd et al., 2005). In fact, if social environments are more complex, less predictable and computationally intractable than nonsocial environments, robustness will be even more important in the former. This does not mean, however, that social intelligence is indistinguishable from nonsocial intelligence. To the extent that heuristics represent problem-specific solutions, social heuristics may consist of some of the 
same building blocks characteristic of nonsocial heuristics (e.g., order search, aspiration levels) but are likely to also include genuinely social building blocks such as emotions and social norms.

Table 1 lists twelve heuristics that are candidate models for social heuristics in the adaptive toolbox of Homo heuristicus (a term coined by Gigerenzer \& Brighton, 2009). Of course, the table does not claim completeness; it describes the heuristics that we discuss next in games against nature and social games. We first consider manifestations of social intelligence in terms of (a) the exploitation of socially distributed information, (b) social learning, and (c) social decision-making in games against nature.

\section{SOCIAL INFORMATION IN GAMES AGAINST NATURE}

Benefiting from others does not require their presence. Consider the quintessential solitary castaway, Robinson Crusoe (Defoe, 1719/1980). Although he was confronted with a myriad of novel problems-games against nature such as locating fresh water, finding shelter from the sun, and treating himself against fever-and although, prior to Friday's arrival, he could not seek anyone's advice, he could still benefit from social information stored in memory, for instance, by remembering how others operate cultural artifacts such as tools. Social information consists in knowledge of other people's behaviors, attributes, intentions, and preferences. Consider, for instance, the task of predicting the magnitude of risks in one's environment (e.g., Hertwig, Pachur, \& Kurzenhäuser, 2005). Following September $11^{\text {th }}$, many people considered alternatives to flying and worried about the safety of various means of long-distance transportation. Lacking official statistics, one way to gauge which of two means of transportation, say, taking the train or taking a cross-country bus, involves a higher risk is to forage information distributed in one's social environment. One hypothesis about how people harvest such information is the social-circle heuristic (Pachur, Hertwig, \& Rieskamp, in press; Pachur, Rieskamp, \& Hertwig, 2005). Like the take-the-best strategy, it embodies sequential search and one-reason decision-making but rather than retrieving probabilistic cues it retrieves instances of the target events in question. The heuristic proceeds as follows:

Search rule. Search through social circles in order of their proximity to the decision maker, beginning with the self circle, followed by the family, friends, and acquaintances circles. Look up the instances of the class of events in questions (e.g., experienced accidents involving trains vs. cross-country buses) in the most proximate circle first, and tally them.

Stopping rule. If one class of events has a higher value (i.e., more instances) than the other, then stop search and proceed to the next step; otherwise search the next circle. If the least proximate circle does not discriminate, guess.

One-reason decision-making. Predict that the event with the higher tally has the higher value on the criterion (e.g., is more risky).

The social-circle heuristic suggests that the external hierarchical structure of a person's social network, measured in terms of degree of kin relationship (oneself, family; Hamilton, 1964) and reciprocal relationship (friends, acquaintances), 
primes the order of search for social information in the person's cognitive space. Such a search policy is adaptive because the individuals probed by the social circle heuristics tend to be those about whom we have the most extensive, accessible, reliable, and veridical knowledge.

Like the availability heuristic (Tversky \& Kahneman, 1973), the social-circle heuristic samples instances but unlike the former it does so in a sequential and ordered way. The assumption that search starts with one's own experiences is consistent with the argument that the self acts as a super-ordinate schema facilitating encoding and subsequent retrieval of information (e.g., Rogers, Kuiper, \& Kirker, 1977). There are now several studies that have analyzed the performance of the heuristic, relative to other heuristics and complex search models, and the conditions under which people use the social-circle heuristic (Pachur, Hertwig, et al., in press; Pachur et al., 2005).

\section{SOCIAL LEARNING IN GAMES AGAINST NATURE}

Firefighters predict how fires will progress from cues such as smoke and roof "sponginess" (Klein, 1998). These cues and, more generally, the cues on which people base their inductive inferences are typically uncertain: sometimes there's no smoke even where there's fire. For this reason, the individual learning of cue validities, apart from being computationally taxing (Juslin \& Persson, 2002, p. 575; but see also footnote 10), can be dangerous. And in fact, individuals appear not to be particularly good and quick learners of cue validities (e.g., Todd \& Dieckmann, in press). There are, however, alternatives to the individual learning of cues validities: They can be built in by evolution (e.g., as appears to be the case for cues indicative of mate value in humans and other animals; Gibson, 1996), and they can be learned socially. Referring to the latter way of learning about cues, Richerson and Boyd (2005, p. 145) emphasized that social learning can "cut the cost of individual learning by allowing individuals to use environmental cues selectively."

Can social learning of cue orders indeed help us overcome the difficulties of individual learning? Using simulations and experiments, Garcia-Retamero, Takezawa, and Gigerenzer $(2006,2007)$ showed that by repeatedly trading information about the cue orders that agents have acquired during individual learning trials, groups of individuals can learn good cue orders in less time and based on less information, relative to individual learning. The authors analyzed several social learning rules (adapted from social decision schemes; Davis, 1973; Hastie \& Kameda, 2005), among them the following three:

The average rule. Each group member estimates the validity of each cue, and the group computes the mean validity across all members for that cue. The cues are then sorted in descending order of their mean validities.

The majority rule. Each group member assigns one vote to the cue with the highest validity, and the cue that receives the most votes is placed first in the rank order. This procedure is repeated for the remaining cues until all cues are placed.

The best-member rule. All members of the group use the cue order of the member who achieved the highest accuracy in the last trials. 
Social heuristic
Social circle heuristic (Pachur, Hertwig,
Rieskamp, in press; Pachur, Rieskamp,

\& Hertwig, 2005)

Imitate the majority heuristic (Boyd \&

Richerson, 2005)

Imitate the successful heuristic (Boyd \& Richerson, 2005)

Averaging heuristic (e.g., Soll \& Larrick, 2009)

Choosing heuristic (e.g., Soll \& Larrick, 2009)

Group recognition heuristic (Reimer \& Katsikopoulos, 2004)

Plurality vote-based lexicographic heuristic (Reimer \& Hoffrage, 2006)

\section{Definition ${ }^{1}$}

Infer which of two alternatives has the higher value by searching through social circles in order of their proximity to the self (self, family, friends, \& acquaintances), stopping the search as soon as the number of instances of one alternative within a circle exceeds that of the other, choosing the

alternative with the higher tally

Look at a majority of people in your reference group, and imitate their behavior

Look for the most successful person in your reference group and imitate his or her behavior

Average quantitative predictions from several advisors using equal weights

Choose among the quantitative predic-

tions from several advisors using cues for expertise

Group choice is determined by those group members who can use the recognition heuristic

Group members first individually decide according to the take-the-best heuristic (Gigerenzer \& Goldstein, 1996) given the cue information individually available to them and then the group chooses the alternative with the most votes

\section{Domain}

Example

Use of social information in game against nature

Social learning in games against nature and social games

Social learning in games against nature and social games

Social learning in games against nature

Social learning in games against nature

Social decision making in games against nature

Social decision making in games against nature
When deciding between two similar restaurants, people tend to choose the restaurant with the longer waiting queue (Raz \& Ert, 2008)

Social learning of cue orders for lexicographic strategies (Garcia-Retamero, Takezawa, \& Gigerenzer; 2006, 2007; see text)

Predicting the profitability of a fund based on several, differing forecasts (see text)

Predicting the profitability of a fund based on several, differing forecasts (see text)

Inferring in a group which of two movies' box office return was higher during their debut weekend (see text)

Choosing among job candidates described by several attributes (expertise, agreeableness, etc.) 
Equity heuristic ( $1 / \mathrm{N}$ rule)

Status tree (Fischbacher, Hertwig, \& Bruhin, in press)

Regret matching heuristic (e.g., Hart, 2005

Tit-for-tat (Axelrod, 1984)

Generous tit-for-tat (Nowak \& Sigmund, 1992)

Mirror heuristic (Howard, 1988; Johnson \& Smirnov, 2008)
Resources are equally distributed among $N$ available options, people etc.

Accept an allocation if it is larger than zero, and as good or better than the proposer's income. Otherwise, accept it, if your share is as good or better than the share in the forgone alternative; otherwise, reject

Stay with the current action if you do not have any regret. If you have regret, switch to the other action with a probability proportional to the amount of regret

Cooperate first. Cooperate if your partner cooperates; otherwise defect

Cooperate first. Cooperate if your partner cooperates; otherwise, cooperate with probability $q$ and defect with probability 1-q

Determine whether you are related to your coplayer. If so, cooperate; otherwise defect
Resources allocation in social games involving related and

Resource allocation in social games

Social games (large set of iterated Battle of the sexes social games)

Social games (iterated prisoner's dilemma)

Social games (iterated prisoner's dilemma) anonymous players

Parental resource allocation among children in families (Hertwig, Davis, \& Sulloway, 2002; see text)

Ultimatum game (see text)

Social games (iterated prisoner's dilemma)

Note. The domain column is not exhaustive. Some heuristics can also be applied in nonsocial domains (e.g., 1/N rule in investment decisions; DeMiguel et al., 2009); here, we focus on their applications in social domains.

${ }^{1}$ For formal definitions, see references. 
Emulating the best member, and thereby forgoing the aggregation of information employed by the other rules, achieved the best performance. Take-the-best's inferential accuracy using the cue order of the best member rule markedly surpassed take-the-best's accuracy based on individual learning (and assuming comparable amounts of learning experience). Copying the best member yielded approximately the same performance as ordering cues according to their ecological validity (both $73 \%$ correct inferences). Impressively, the best-member rule reaped a large portion of its superior performance even after a single exchange of social information. Experimental results supported those of the simulations: Social learners adopted superior cue orders, relative to individual learners, thus making more accurate inferences. In addition, the best-member rule explained best how people used the information received from others to arrive at a socially constructed cue order.

The best-member rule embodies the strategy of imitation. Social learning in the form of imitation (or, relatedly, advice giving) allows individuals to learn about their environment without engaging in potentially hazardous learning trials or wasting a large amount of time and energy on exploration (e.g., Henrich \& McElreath, 2003; Laland, 2001). Imitation, a prime example of social intelligence, is particularly versatile in that it can be more nuanced than an unconditional "dowhat-others-do" strategy. Depending on situational cues and opportunities, the behavior copied may be that exhibited by the majority, by the most successful individuals (as in the above example; Boyd \& Richerson, 2005), or by the nearest individual. The crucial point is that using any variant of imitation (or even simpler forms of social learning; see Noble \& Todd, 2002) can speed up and foster decision making by reducing the need for direct experience and information gathering.

Still another route through which social learning can occur is by actively seeking the advice of others (rather than by just probing socially distributed information, for instance, as the social-circle heuristic would do), and by interpreting institutional arrangements as implicit recommendations (e.g., policy defaults; McKenzie, Liersch, \& Finkelstein, 2006). Advice taking can be seen as an adaptive social decision-support system that compensates for an individual's blind spots (Yaniv \& Milyavsky, 2007). But how helpful is others' advice? And what if the others' wisdom is widely diverging or conflicts with one's own opinion? Consider a fund manager who aims to predict the profitability of an investment tool (a game against nature). After asking each of her colleagues for his or her best profitability estimate, she ends up with a heterogeneous set of numbers. How should she make use of them? From a prescriptive viewpoint, averaging the estimates is an excellent strategy under a wide range of situations (e.g., Armstrong, 2001; Clemen, 1989; Soll \& Larrick, 2009; Yaniv, 2004). If her colleagues produce estimates with differing errors (e.g., some under- and some overestimate the true value), then averaging will necessarily have a smaller absolute error, relative to randomly picking one estimate. The reason is that the errors will cancel each other out in the average. If all estimates share the same errors (e.g., all advisors overestimate profitability), then averaging and randomly choosing are equally accurate. Therefore, in the long run averaging is the dominant strategy (e.g., Larrick \& Soll, 2006). Even better, the benefits of averaging grow and level off quickly; therefore, probing advice from a few people and combining the numbers suffices (e.g., Hogarth, 1978). However, taking advice and averaging it with one's own opinion is not part of everybody's mental repertoire; in a set of studies, about a third of people tended to discount the advice and stuck with their initial own estimate, another third tended to average advice and 
their own opinion, and the final third employed both strategies (Soll \& Larrick, 2009, see Table 1).

In sum, averaging the advice from different people is an efficient heuristic to tap into the wisdom of crowds (Surowiecki, 2004). To benefit from the wisdom of averaging competing opinions, however, does not even require the company of others. Recently, Herzog and Hertwig (2009) demonstrated that by using the technique of "dialectical bootstrapping" a person, in principle, could simulate the wisdom of crowds within the bounds of his or her mind. Specifically, by probing his or her own knowledge twice, each time assuming a different point of view and averaging the resulting opinions, a person can boost her inferential accuracy.

\section{SOCIAL DECISION MAKING IN GAMES AGAINST NATURE}

How to combine diverging pieces of advice is a problem tantamount to that which groups encounter when they aim to reach a collective judgment or decision. How should the opinion, judgment, or inference of each member be weighted and merged with the others to arrive at a final verdict? A vast literature on information aggregation in groups has addressed this and related questions (e.g., Einhorn, Hogarth, \& Klempner, 1977; Gigone \& Hastie, 1997; Hastie \& Kameda, 2005). Studying the use of the simple recognition heuristic (see above) in a group context, Reimer and Katsikopoulos (2004) arrived at the counterintuitive insight that under specific conditions, lack of recognition should and does trump the conflicting knowledge of a majority of people. For illustration, consider the task of predicting which of two recently released movies had the better box office return during their debut weekend. The task of a group of three people is to find the correct answer through discussion. The following conflict could arise: Two group members have heard of both movies and both think, independently of each other, that movie $A$ has grossed more money than $B$. The third member-not a movie buff-has never heard of $A$ and infers, using the recognition heuristic, that $B$ made more money. What then will and should the final verdict of the group be? Reimer and Katsikopoulos showed that, surprisingly, in nearly three fifths (59\%) of all cases the group did not predict $A$, the answer the majority rule would have suggested, but $B$; this number rose to $76 \%$ when two members resorted to recognition. This seemingly odd behavior of the group did increase its accuracy. Analytically, Reimer and Katsikopoulos showed that when the (average) recognition validity $\alpha$ is larger than the (average) knowledge validity $\beta$, then a group that recognizes fewer objects (movies) will perform better than a group that recognizes more. Judging from Reimer and Katsikopoulos' results, group members seem to grasp and trust the recognition heuristic and the wisdom encapsulated in partial ignorance (see Reimer \& Hoffrage, 2006, for more on simple group heuristics).

Let us conclude with one further aspect of group decision-making that has received scant attention: A group per se can represent an adaptive toolbox of heuristics. Typically, the toolbox metaphor describes the view that the individual mind commands a collection of different mental tools (e.g., Gigerenzer \& Todd, 1999) enabling adaptive responses tailored to different decision-making environments (after, for instance, a period of individual reinforcement learning; Rieskamp \& Otto, 2006). The same logic can be applied to the collective mind of the group (see Kameda \& Tindale, 2006). Specifically, by taking advantage of the fact that differ- 
ent people tend to employ different strategies (e.g., Payne et al., 1993), a group can recruit heuristics from a suite of strategies (see also Page, 2007) that is even richer than that of the individual mind. Moreover, the group has the luxury of being able to observe how different heuristics perform in the same environment (by permitting different people to apply the strategy they would have selected). Based on their members' individual success, the group can assess the success of each heuristic, pinpoint the frontrunner, and apply it routinely. In this sense, a group has the potential to act even more ecologically rational than the individual mind.

\section{SOCIAL GAMES}

We now turn to social games, that is, to exchanges between two or more agents. As with games against nature, we suggest that much of the decision-making processes in this social context can be described in terms of boundedly rational simple heuristics. We illustrate this thesis with two examples, the equity heuristic, and fast and frugal trees in the ultimatum game.

Equity Heuristic. The equity heuristic (sometimes called $1 / N$ rule) is an example to support our conjecture that the cognitive processes of social intelligence may not be qualitatively different from the processes of nonsocial intelligence. This heuristic has been proposed to describe how people invest their resources in $N$ options, with the options referring both to social (e.g., children) and nonsocial entities (e.g., saving options for retirement). Although derided as being naïve by behavioral economists such as Benartzi and Thaler (2001), the heuristic can outperform optimizing strategies in environments with a large degree of uncertainty, a large number of assets, and with small learning samples. As DeMiguel, Garlappi, and Uppal (2009) have shown, under such environmental circumstances, the simple heuristic, devoid of any estimated parameter, yielded better performance on various measures of success than optimal asset allocation strategies.

The use of the equity heuristic is not restricted to financial decisions. It may also capture how many contemporary parents invest their limited resources into their offspring (Hertwig et al., 2002). Parental resources such as affection, time, and money (e.g., for education) are notoriously limited, and parents with more than one child need to constantly decide how to allocate their resources among their $N$ children (consistent with parents' expressed values in egalitarian societies; Hertwig et al.). It specifies that parents attempt to split resources equally among all $N$ children at any given investment period. This simple heuristic has several interesting properties. By implementing an equal (fair) allocation of resources, it takes into account parents' inequality aversion (e.g., Bolton \& Ockenfels, 2000; Fehr \& Schmidt, 1999). In addition, it permits parents to easily justify their allocation decisions to the "stakeholders" in the family, for instance, quarreling children and observant grandparents; and it allows parents to (sometimes) hand over the actual implementation of the allocation to their children. ${ }^{11}$ Yet, the heuristic is not

11. Parents can make use of the time-honored heuristic, "I cut, you choose", in which one sibling divides the cake (or a chore) in two parts that she likes equally well, and the other one gets to pick the piece he prefers. For more than two children, other strategies, for instance, the moving knife-strategy, have been proposed to produce envy-free allocations. These strategies, however, quickly become complex (Brams \& Taylor, 1996). 
a panacea. Although each single allocation decision is fair, the equity heuristic predicts inequalities on higher levels of aggregation-a phenomenon reminiscent of Schelling's (1978) analysis of unexpected macro-consequences of reasonable micro-motives. For illustration, consider the limited resource of parental time. According to the equity heuristic, the cumulative distribution will be unequal, with middleborns receiving less care time than first and lastborns. The reason is that middleborns never enjoy a period of exclusive attention in the family (see Hertwig et al. for evidence that supports this and other predictions). ${ }^{12}$

Fast and Frugal Trees. As described earlier, the ultimatum game has become the bogey for classic economists. A simple bilateral two-person strategic situation with perfect information produces robust behavior that is inconsistent with the classical economic prediction. The dominant response among those economists who accepted the reliability of the behavior was to assimilate the behavior into the existing utility framework by modifying the utility function. Rather than retaining the universal utility calculus, however, one could heed Rubinstein's (2003) call and begin "to open the black box of decision making, and come up with some completely new and fresh modeling devices" (p. 1215). Fischbacher, Hertwig, and Bruhin (in press) did so by using the building blocks of fast and frugal heuristics to shed light on the processes in the ultimatum game. Focusing on mini-ultimatum games, in which the proposer chooses between two fixed income distributions for both players-for example, 3:5 versus 2:8 - and the responder gets to accept or reject it, Fischbacher et al. modeled people's choice in terms of fast and frugal decision trees. A fast and frugal tree is defined as a classification tree that allows for a classification at each level of the tree (Martignon, Vitouch, Takezawa, \& Forster, 2003). A fast and frugal tree consists of the same building blocks as the take-thebest heuristic: ordered search, one-reason stopping rule, and decision making on the basis of one reason.

For illustration, the status tree, one of four decision trees proposed by Fischbacher et al. (in press), consists of three criteria for rejecting or accepting an allocation. The first criterion simply checks whether the offered allocation is larger than zero. If so, a Homo economicus would accept it, regardless of its size. According to the status tree, however, a person next considers the status criterion. It involves a social comparison: If the proposer selects the allocation in which the responder does, relative to the proposer, at least as well, the responder will invariably accept it. No other reason enters her decision. If that is not the case (here: $2<8$ ), however, she does not reflexively reject. Rather, she now considers a third criterion that involves a comparison between the actual and the forgone allocation, the kindness criterion. If the responder does at least as well as in the forgone distribution (here yes: 3 > 2 ), she will accept the offered allocation. Only if the allocation also fails this test in kindness, she will reject.

12. The proportion of parents who aim to treat their children equally is hard to gauge. Whereas some studies find evidence consistent with the equity heuristic (e.g., Price, 2008) others report that "Despite a powerful social norm that parents should treat offspring equally ..., parents often differentiate among their children in such domains as closeness, support, and control" (Suitor, Sechrist, Plikuhn, Pardo, \& Pillemer, 2008, p. 334). Importantly, however, Hertwig et al. (2002, p. 741) showed that the counterintuitive inequalities in resource distribution resulting from the equity heuristic - although smaller in size-will continue to exist even if parents attempted to find a reasonable compromise between equity and children's differential age-specific needs (Hertwig et al., 2002, p. 741). 
Depending on their depth of reasoning, Fischbacher et al. (in press) described people in terms of fast and frugal trees involving one, three, or four criteria. Modeling responders' decisions in terms of such trees enables tests both of decision and process. Recall that the status trees assume a sequential process of examining three criteria that can be stopped at the first or second criterion. Therefore, the tree predicts that the more criteria are examined, the more time is required to make a decision. Specifically, the status tree predicts that accepting an allocation based on the kindness criterion (comparison with one's forgone payoff) rather than the status criterion (comparison with proposer's payoff) should take longer. Indeed, in Fischbacher et al.'s study, people took significantly more time to accept allocations that failed the status test but passed the kindness test, relative to allocations that passed the status test. Explaining such differences in response times requires a process model, and thus can hardly be accounted for by social preference models.

Of course, models of heuristics are not new in studies of social games. The titfor-tat strategy and its relatives such as generous tit-for-tat (e.g., Axelrod, 1984; Nowak \& Sigmund, 1992), for instance, belong to the most famous models of simple strategies (see also Howard, 1988; Johnson \& Smirnov, in press; Rieskamp \& Todd, 2006). Another class of simple heuristics in social games is regret based (e.g., Hart, 2005). Regret is an emotion that enables us to relate the outcome of a previous decision to what we would have obtained had we opted for the rejected alternative. Hart's regret-matching heuristic suggests that a person will continue with the current action if she does not have any regret. If she has regret, she will switch to the other action with a probability proportional to the amount of regret. ${ }^{13}$ Hart concluded from his analytical results that "simple and far-from-rational behavior in the short run [based on regret avoidance] may well lead to fully rational outcomes in the long run" (p. 1415).

\section{FROM HOMO AUTISTICUS TO HOMO HEURISTICUS}

Let us return to the analogy between Homo economicus and autism. Autism is a disorder. In their book, The Unwritten Rules of Social Relationships, Grandin and Barron (2004) described manifold mysteries of social interactions from the viewpoint of an autistic mind. These mysteries include, for instance, the facts that not everybody who is nice to me is my friend; that honesty is different than diplomacy; and that fitting in is often tied to looking and sounding like you fit in. As these rules indicate, nonautistic people are able to differentiate sophisticated social behavior, or in other words, they are socially intelligent. Given this intelligence, economic theory and theories of human rationality deserve a psychologically more realistic point of departure than that of an autist puzzled by social mysteries, or that of an anthropologist studying Martians. Psychologically plausible models of ecologically and socially smart heuristics could be such a starting point. Let us get to know this Homo heuristicus.

13. Regret at any moment is defined as the amount by which the payoff earned by a person is exceeded by the payoff she would have earned had she always chosen the other action. 


\section{REFERENCES}

Anderson, J. R., \& Lebiere, C. (1998). The atomic components of thought. Mahwah, NJ: Erlbaum.

Armstrong, J. S. (2001). Combining forecasts. In J. S. Armstrong (Ed.), Principles of forecasting: A handbook for researchers and practitioners (pp. 417-439). New York: Kluwer.

Axelrod, R. (1984). The evolution of cooperation. New York: Basic Books.

Barber, B. M., \& Odean, T. (2000). Trading is hazardous to your wealth: The common stock investment performance of individual investors. Journal of Finance, 55, 773-806.

Barber, B. M., \& Odean, T. (2001). Boys will be boys: Gender, overconfidence, and common stock investment. Quarterly Journal of Economics, 116, 261-292.

Bazerman, M. H., \& Moore, D. (2008). Judgment in managerial decision making (7th ed.). New York: Wiley \& Sons.

Benartzi, S., \& Thaler, R. (2001). Naïve diversification strategies in defined contribution saving plans. American Economic Review, 91, 79-98.

Bell, D. (1985). Disappointment in decision making under uncertainty. Operations Research, 33, 1-27.

Bernoulli, D. (1738/1954). Exposition of a new theory on the measurement of risk. Econometrica, 22, 23-36.

Berretty, P. M., Todd, P. M., \& Martignon, L. (1999). Categorization by elimination: Using few cues to choose. In G. Gigerenzer, P. M. Todd, \& the ABC Research Group (Eds.), Simple heuristics that make us smart (pp. 235-254). New York: Oxford University Press.

Binmore, K. (2005). Economic man-or straw man? Behavioral and Brain Sciences, 28, 817-818.

Blount, S. (1995). When social outcomes aren't fair: The effect of causal attributions on preferences. Organizational Behavior and Human Decision Processes, 63, 131-144.

Bolton, G. E., \& Ockenfels, A. (2000). ERC-A theory of equity, reciprocity, and competition. American Economic Review, 90, 166-193.

Boyd, R., \& Richerson, P. J. (2005). The origin and evolution of cultures. New York: Oxford University Press.
Brams, S. J., \& Taylor, A. D (1996). Fair division: From cake-cutting to dispute resolution. Cambridge, UK: Cambridge University Press.

Brandstätter, E., Gigerenzer, G., \& Hertwig, R. (2006). The priority heuristic: Making choices without trade-offs. Psychological Review, 113, 409-432.

Brandstätter, E., Gigerenzer, G., \& Hertwig, R. (2008). Risky choice with heuristics: Reply to Birnbaum (2008), Johnson, Schulte-Mecklenbeck, \& Willemsen (2008), and Rieger \& Wang (2008). Psychological Review, 115, 281-289.

Bröder, A. (in press). The quest for take the best-Insights and outlooks from experimental research. In P. M. Todd, G. Gigerenzer, \& the ABC Research Group (Eds.), Ecological rationality: Intelligence in the world. New York: Oxford University Press.

Bröder, A., \& Eichler, A. (2006). The use of recognition information and additional cues in inferences from memory. Acta Psychologica, 121, 275-284.

Brunswik, E. (1957). Scope and aspects of the cognitive problem. In H. Gruber, K. R. Hammond, \& R. Jessor (Eds.), Contemporary approaches to cognition (pp. 5-31). Cambridge, MA: Harvard University Press.

Busemeyer, J. R., \& Townsend, J. T. (1993). Decision field theory: A dynamic-cognitive approach to decision making in an uncertain environment. Psychological Review, 100, 432-459.

Byrne, R., \& Whiten, A. (Eds.) (1988). Machiavellian intelligence: Social expertise and the evolution of intellect in monkeys, apes and humans. Oxford: Clarendon.

Camerer, C. (1995). Individual decision making. In J. H. Kagel \& A. E. Roth (Eds), The handbook of experimental economics (pp. 587-703). Princeton: Princeton University Press.

Camerer, C. F. (2003). Behavioral game theory: Experiments in strategic interaction. Princeton: Princeton University Press.

Camerer, C. F., \& Fehr, E. (2006). When does "economic man" dominate social behavior? Science, 311, 47-52.

Chapman, G. B., \& Elstein, A. S. (2000). Cognitive processes and biases in medical 
decision making. In G. B. Chapman \& F. S. Sonnenberg (Eds.), Decision making in health care: Theory, psychology, and applications (pp. 183-210). Cambridge, UK: Cambridge University Press.

Clemen, R. T. (1989). Combining forecasts: A review and annotated bibliography. International Journal of Forecasting, 5, 559-583.

Czerlinski, J., Gigerenzer, G., \& Goldstein, D. G. (1999). How good are simple heuristics? In G. Gigerenzer, P. M. Todd, \& the ABC Research Group (Eds.), Simple heuristics that make us smart (pp. 97-118). New York: Oxford University Press.

Darwin (1887/1969). The autobiography of Charles Darwin, 1809-1882. Edited by N. Barlow. New York: Norton. (Original work published 1887).

Davis, J. H. (1973). Group decisions and social interactions: A theory of social decision schemes. Psychological Review, 80, 97-125.

Dawes, R. M. (1979). The robust beauty of improper linear models in decision making. American Psychologist, 34, 571-582.

Defoe, D. (1719/1980). Robinson Crusoe. Harmondsworth, UK: Penguin.

DeMiguel, V., Garlappi, L., \& Uppal, R. (2009). Optimal versus naive diversification: How inefficient is the $1 / \mathrm{N}$ portfolio strategy? Review of Financial Studies, 22, 1915-1953.

Dhami, M. K. (2003). Psychological models of professional decision-making. Psychological Science, 14, 175-180.

Dhami, M. K., Hertwig, R., \& Hoffrage, U. (2004). The role of representative design in an ecological approach to cognition. Psychological Bulletin, 130, 959-988.

Dufwenberg, M., \& Kirchsteiger, G. (2004). A theory of sequential reciprocity. Games and Economic Behavior, 47, 268-298.

Einhorn, H. J., Hogarth, R. M., \& Klempner, E. (1977). Quality of group judgment. Psychological Bulletin, 84, 158-172.

Falk, A., \& Fischbacher, U. (2006). A theory of reciprocity. Games and Economic Behavior, 54, 293-315.

Fehr, E., \& Schmidt, K. M. (1999). A theory of fairness, competition, and cooperation. Quarterly Journal of Economics, 114, 817-868.

Fischbacher, U., Hertwig, R., \& Bruhin, U. (in press). How simple heuristics em- body social intelligence in games. In R. Hertwig, U. Hoffrage \& the ABC Research Group (Eds.), Social heuristics that make us smart. New York: Oxford University Press.

Fischer, J. E., Steiner, F., Zucol, F., Berger, C., Martignon, L., Bossart, W., et al. (2002). Use of simple heuristics to target macrolide prescription in children with community-acquired pneumonia. Archives of Pediatrics and Adolescent Medicine, 156, 1005-1008.

Fischhoff, B. (1982). Debiasing. In D. Kahneman, P. Slovic, \& A. Tversky (Eds.), Judgment under uncertainty: Heuristics and biases (pp. 422-444). New York: Cambridge University Press.

Fiske, S., \& Taylor, S. (1984). Social cognition. Reading, UK: Addison-Wesley.

Fraenkel, A. S., \& Lichtenstein, D. (1981). Computing a perfect strategy for $n * n$ chess requires time exponential in $\mathrm{n}$. Journal of Combinatorial Theory, 31, 199-214.

Garcia-Retamero, R., Takezawa, M., \& Gigerenzer, G. (2006). How to learn good cue orders: When social learning benefits simple heuristics. In R. Sun \& N. Miyake (Eds.), Proceedings of the 28th annual conference of the cognitive science society (pp. 1352-1358). Mahwah, NJ: Erlbaum.

Garcia-Retamero, R., Takezawa, M., \& Gigerenzer, G. (2007). When social learning benefits fast and frugal decision making. Manuscript submitted for publication.

Gardner, D. (2008). Risk: The science and politics of fear. London: Virgin Books.

Gibson, R. M. (1996). Female choice in sage grouse: The roles of attraction and active comparison. Behavioral Ecology and Sociobiology, 39, 55-59.

Gigerenzer, G. (1996). Rationality: Why social context matters. In P. B. Baltes \& U. Staudinger (Eds.), Interactive minds: Lifespan perspectives on the social foundation of cognition (pp. 319-346). Cambridge: Cambridge University Press.

Gigerenzer, G. (1997). The modularity of social intelligence. In A. Whiten \& R. W. Byrne (Eds.), Machiavellian intelligence: Extensions and evaluations (Vol. 2, pp. 264-288). Cambridge, UK: Cambridge University Press.

Gigerenzer, G. (2004). Fast and frugal heuristics: The tools of bounded rationality. In D. J. Koehler \& N. Harvey (Eds.), Black- 
well handbook of judgment and decision making (pp. 62-88). Oxford, UK: Blackwell.

Gigerenzer, G. (2008). Why heuristics work. Perspectives on Psychological Science, 3, 20-29.

Gigerenzer, G., \& Brighton, H. (2009). Homo heuristicus: Why biased minds make better predictions. Topics in Cognitive Science, 1, 107-143.

Gigerenzer, G., Dieckmann, A., \& Gaissmaier, $W$. (in press). Heuristic search as a building block of cognition. In P. M. Todd, G. Gigerenzer, \& the ABC Research Group (Eds.), Ecological rationality: Intelligence in the world. New York: Oxford University Press.

Gigerenzer, G., \& Engel, C. (Eds.) (2006). Heuristics and the law: Report of the 94th Dahlem workshop on heuristics and the law, Berlin, June 6-11, 2004. Cambridge, MA: MIT Press.

Gigerenzer, G., \& Goldstein, D. G. (1996). Reasoning the fast and frugal way: Models of bounded rationality. Psychological Review, 103, 650-669.

Gigerenzer, G., Hoffrage, U., \& Kleinbölting, H. (1991). Probabilistic mental models: A Brunswikian theory of confidence. Psychological Review, 98, 506-528.

Gigerenzer, G., Hoffrage, U., \& Goldstein, D. G. (2008). Fast and frugal heuristics are plausible models of cognition:. Psychological Review, 115, 230-239.

Gigerenzer, G., \& McElreath, R. (2003). Social intelligence in games. Journal of Institutional and Theoretical Economics, 159, 188-194.

Gigerenzer, G., \& Selten, R. (Eds.) (2001). Bounded rationality: The adaptive toolbox. Cambridge, MA: MIT Press

Gigerenzer, G., \& Todd, P. M. (1999). Fast and frugal heuristics: The adaptive toolbox. In G. Gigerenzer, P. M. Todd, \& the ABC Research Group (Eds.), Simple heuristics that make us smart (pp. 3-34). New York: Oxford University Press.

Gigerenzer, G., Todd, P. M., \& the ABC Research Group. (1999). Simple heuristics that make us smart (G. Gigerenzer, P. M. Todd, \& the ABC Research Group, Eds.). New York: Oxford University Press.

Gigone, D., \& Hastie, R. (1997). Proper analysis of the accuracy of group judgments. Psychological Bulletin, 121, 149-167.
Gilovich, T., Griffin, D., \& Kahneman, D. (Eds.) (2002). Heuristics and biases. The psychology of intuitive judgement. Cambridge, UK: Cambridge University Press.

Glaser, M., Nöth, M., \& Weber, M. (2004). Behavioral finance. In D. J. Koehler \& N. Harvey (Eds.), Blackwell handbook of judgment and decision making (pp. 527-546). Oxford, UK: Blackwell.

Goldstein, D. G. (2007). Getting attention for unrecognized brands. Harvard Business Review, 85, 24-28.

Goldstein, D. G., \& Gigerenzer, G. (2002). Models of ecological rationality: The recognition heuristic. Psychological Review, 109, 75-90.

Gould, S. J. (1992). Bully for brontosaurus: Reflections in natural history. Norton: New York.

Gould, S. J., \& Vrba, E. S. (1982). Exaptation-a missing term in the science of form. $\mathrm{Pa}$ leobiology, 8, 4-15.

Grandin, T., \& Barron, S. (2004). The unwritten rules of social relationships. Arlington, TX: Future Horizons.

Grice, H. P. (1989). Studies in the way of words. Cambridge, MA: Harvard University Press.

Güth, W., Schmittberger, R., \& Schwarze, B. (1982). An experimental analysis of ultimatum bargaining. Journal of Economic Behavior and Organization, 3, 367-388.

Güth, W., \& Tietz, R. (1990). Ultimatum bargaining behaviour: A survey and comparison of experimental results. Journal of Economic Psychology, 11, 417-449.

Hamilton, W. D. (1964). The genetical evolution of social behaviour I and II. Journal of Theoretical Biology, 7, 1-52.

Hammond, K. R. (1996). Human judgment and social policy: Irreducible uncertainty, inevitable error, unavoidable injustice. New York: Oxford University Press.

Harrison, G. W. (1994). Expected utility theory and the experiments. Empirical Economics, 19, 223-253.

Hart, S. (2005). Adaptive heuristics. Econometrica, 73, 1401-1430.

Hastie, R., \& Kameda, T. (2005). The robust beauty of majority rules in group decisions. Psychological Review, 112, 494-508.

Henrich, J., Boyd, R., Bowles, S., Camerer, C. F., Fehr, E., Gintis, H., et al. (2005). "Economic man" in cross-cultural perspective: Behavioral experiments in 15 
small-scale societies. Behavioral and Brain Sciences, 28, 795-815.

Henrich, J., \& McElreath, R. (2003). The evolution of cultural evolution. Evolutionary Anthropology, 12, 123-135.

Hertwig, R., Benz, B., \& Krauss, S. (2008). The conjunction fallacy and the many meanings of and. Cognition, 108, 740-753.

Hertwig, R., Davis, J. N., \& Sulloway, F. J. (2002). Parental investment: How an equity motive can produce inequality. Psychological Bulletin, 128, 728-745.

Hertwig, R., \& Gigerenzer, G. (1999). The 'conjunction fallacy' revisited: How intelligent inferences look like reasoning errors. Journal of Behavioral Decision Making, 12, 275-305.

Hertwig, R., Herzog, S. M., Schooler, L. J., \& Reimer, T. (2008). Fluency heuristic: A model of how the mind exploits a byproduct of information retrieval. Journal of Experimental Psychology: Learning, Memory, and Cognition, 34, 1191-1206.

Hertwig, R., \& Hoffrage, U. (in press). The $\mathrm{ABCs}$ of social rationality: A research program. In R. Hertwig, U. Hoffrage \& the ABC Research Group (Eds.), Social heuristics that make us smart. New York: Oxford University Press.

Hertwig, R., Hoffrage, U., \& Martignon, L. (1999). Quick estimation: Letting the environment do the work. In G. Gigerenzer, P. M. Todd, \& the ABC Research Group (Eds.), Simple heuristics that make us smart (pp. 209-234). New York: Oxford University Press.

Hertwig, R., \& Ortmann, A. (2001). Experimental practices in economics. A methodological challenge for psychologists? Behavioral and Brain Sciences, 24, 383-451.

Hertwig, R., Pachur, T., \& Kurzenhäuser, S. (2005). Judgments of risk frequencies: Tests of possible cognitive mechanisms. Journal of Experimental Psychology: Learning, Memory and Cognition, 31, 621-642.

Hertwig, R., \& Todd, P. M. (2003). More is not always better: The benefits of cognitive limits. In D. Hardman \& L. Macchi (Eds.), Thinking: Psychological perspectives on reasoning, judgment and decision making (pp. 213-231). Chichester, UK: Wiley.

Herzog, S. M., \& Hertwig, R. (2009). The wisdom of many in one mind: Improving individual judgments with dialectical bootstrapping. Psychological Science, 20, 231-237.

Hilton, D. J. (1995). The social context of reasoning: Conversational inference and rational judgment. Psychological Bulletin, $118,248-271$.

Hoffrage, U., Hertwig, R., \& Gigerenzer, G. (2000). Hindsight bias: A by-product of knowledge updating? Journal of Experimental Psychology: Learning, Memory, and Cognition, 26, 566-581.

Hogarth, R. M. (1978). A note on aggregating opinions. Organizational Behavior and Human Performance, 21, 40-46.

Hogarth, R. M., \& Karelaia, N. (2006). "Takethe-best" and other simple strategies: Why and when they work "well" with binary cues. Theory and Decision, 61, 205-249.

Hogarth, R. M., \& Karelaia, N. (2007). Heuristic and linear models of judgment: Matching rules and environments. Psychological Review, 114, 733-758.

Howard, J. V. (1988). Cooperation in the Prisoner's Dilemma. Theory and Decision, 24, 203-213.

Hoyer, W. D., \& Brown, S. P. (1990). Effects of brand awareness on choice for a common, repeat-purchase product. Journal of Consumer Research, 17, 141-148.

Hsu, M., Bhatt, M., Adolphs, R., Tranel, D., \& Camerer, C. F. (2005). Neural systems responding to degrees of uncertainty in human decision-making. Science, 310, 1680-1683.

Humphrey, N. K. (1976/1988). The social function of intellect. In R. Byrne \& A. Whiten (Eds.), Machiavellian intelligence: Social expertise and the evolution of intellect in monkeys, apes, and humans (pp. 13-26). Oxford, UK: Clarendon. (originally published 1976)

Inhelder, B., \& Piaget, J. (1964). The early growth of logic in the child. New York: Norton.

Johnson, T., \& Smirnov, O. (in press). Social heuristics and the evolution of cooperation. In R. Hertwig, U. Hoffrage \& the ABC Research Group (Eds.), Social heuristics that make us smart. New York: Oxford University Press.

Juslin, P., \& Persson, M. (2002). PROBabilities from EXemplars/PROBEX: A "lazy" algorithm for probabilistic inference from generic knowledge. Cognitive Science, 26, 563-607. 
Juslin, P., Winman, A., \& Olsson, H. (2000). Naïve empiricism and dogmatism in confidence research: A critical examination of the hard-easy effect. Psychological Review, 107, 384-396.

Kahneman, D. (2003). A perspective on judgment and choice: Mapping bounded rationality. American Psychologist, 58, 697-720.

Kahneman, D., Slovic, P., \& Tversky, A. (1982). Judgment under uncertainty: Heuristics and biases. New York: Cambridge University Press.

Kahneman, D., \& Tversky, A. (1972). Subjective probability: A judgment of representativeness. Cognitive Psychology, 3, 430-454.

Kahneman, D., \& Tversky, A. (1979). Prospect theory: An analysis of decision under risk. Econometrica, 47, 263-292.

Kameda, T., \& Tindale, R. S. (2006). Groups as adaptive devices: Human docility and group aggregation mechanisms in evolutionary context. In M. Schaller, J. Simpson, \& D. Kenrick (Eds.), Evolution and social psychology. New York: Psychology Press.

Katsikopoulos, K. V., Schooler, L., \& Hertwig, R. (2009). The robust beauty of mediocre information. Manuscript submitted for publication.

Kirchsteiger, G. (1994). The role of envy in ultimatum games. Journal of Economic Behavior and Organization, 25, 373-389.

Klein, G. (1998). Sources of power: How people make decisions. Cambridge, MA: The MIT Press.

Koenigs, M., \& Tranel, D. (2008). Prefrontal cortex damage abolishes brand-cued changes in cola preference. Social Cognitive and Affective Neuroscience, 3, 1-6.

Koenigs, M., Young, L., Adolphs, R., Tranel, D., Cushman, F., Hauser, M., \& Damasio, A. (2007). Damage to the prefrontal cortex increases utilitarian moral judgments. Nature, 446, 908-911.

Krueger, J. I., \& Funder, D. C. (2004). Towards a balanced social psychology: Causes, consequences, and cures for the problem-seeking approach to social behavior and cognition. Behavioral and Brain Sciences, 27, 313-327.

Krueger, J. I., Massey, A., \& DiDonato, T. E. (2008). A matter of trust: From social preferences to the strategic adherence to social norms. Negotiation and Conflict Management Research, 1, 31-52.

Kummer, H., Daston, L., Gigerenzer, G., \& Silk, J. B. (1997). The social intelligence hypothesis. In P. Weingart, P. J. Richerson, S. D. Mitchell, \& S. Maasen (Eds.), Human by nature. Between biology and the social sciences (pp. 157-179). Hillsdale, NJ: Erlbaum.

Laland, K. (2001). Imitation, social learning, and preparedness as mechanisms of bounded rationality. In G. Gigerenzer \& R. Selten (Eds.), Bounded rationality: The adaptive toolbox (pp. 233-248). Cambridge, MA: MIT Press.

Larrick, R. P., \& Soll, J. B. (2006). Intuitions about combining opinions: Misappreciation of the averaging principle. Management Science, 52, 111-127.

Levine, D. K. (1998). Modeling altruism and spitefulness in experiments. Review of Economic Dynamics, 1, 593-622.

Lewin, K., Dembo, T., Festinger, L., \& Sears, P. S. (1944). Level of aspiration. In J. McV. Hunt (Ed.), Personality and the behavioral disorders. (Vol. 1,pp. 333-378). New York: Ronald Press.

Loomes, G., \& Sugden, R. (1982). Regret theory: An alternative theory of rational choice under uncertainty. The Economic Journal, 92, 805-824.

March, J., \& Simon, H. A. (1958/1993). Organizations (2nd ed.). Cambridge, MA: Blackwell. (first published in 1958).

Martignon, L., \& Hoffrage, U. (2002). Fast, frugal and fit: Simple heuristics for paired comparison. Theory and Decision, 52, 29-71.

Martignon, L., Vitouch, O., Takezawa, M., \& Forster, M. R. (2003). Naive and yet enlightened: From natural frequencies to fast and frugal decision trees. In D. Hardman \& L. Macchi (Eds.), Thinking: Psychological perspectives on reasoning, judgment, and decision making (pp. 189-211). Chichester, UK: Wiley.

McKenzie, C. R. M., Liersch, M. J., \& Finkelstein, S. R. (2006). Recommendations implicit in policy defaults. Psychological Science, 17, 414-420.

Mellers, B. A. (2000). Choice and the relative pleasure of consequences. Psychological Bulletin, 126, 910-924.

Mellers, B., Hertwig, R., \& Kahneman, D. (2001). Do frequency representations 
eliminate conjunction effects? An exercise in adversarial collaboration. Psychological Science, 12, 269-275.

Miller, G. F., \& Todd, P. M. (1998). Mate choice turns cognitive. Trends in Cognitive Sciences, 2, 190-198.

Mitchell, T. M. (1997). Machine learning. New York: McGraw-Hill.

Mosteller, F. (1987). Fifty challenging problems in probability with solutions. New York: Dover Publications.

Myung, I. J. (2000). The importance of complexity in model selection. Journal of Mathematical Psychology, 44, 190-204.

Nagel, R. (1995). Unraveling in guessing games: An experimental study. The American Economic Review, 85, 1313-1326.

Newell, B. R., \& Fernandez, D. (2006). On the binary quality of recognition and the inconsequentiality of further knowledge: Two critical tests of the recognition heuristic. Journal of Behavioral Decision Making, 19, 333-346.

Nisbett, R. E., \& Ross, L. D. (1980). Human inference: Strategies and shortcomings of social judgment. Englewood Cliffs, NJ: Prentice-Hall.

Noble, J., \& Todd, P. M. (2002). Imitation or something simpler? Modelling simple mechanisms for social information processing. In K. Dautenhahn \& C. Nehaniv (Eds.), Imitation in animals and artifacts (pp. 423-439). Cambridge, MA: MIT Press.

Nowak, M. A., \& Sigmund, K. (1992). Tit for tat in heterogeneous populations. Nature, 355, 250-253.

Oppenheimer, D. M. (2003). Not so fast! (and not so frugal!): Rethinking the recognition heuristic. Cognition, 90, B1-B9.

Ortmann, A., \& Hertwig, R. (2008). Why anomalies cluster in experimental tests of one-shot and/or finitely repeated games: Some evidence from psychology. Manuscript in preparation.

Pachur, T., \& Biele, G. (2007). Forecasting from ignorance: The use and usefulness of recognition in lay predictions of sports events. Acta Psychologica, 125, 99-116.

Pachur, T., Bröder, A., \& Marewski, J. N. (2008). The recognition heuristic in memorybased inference: Is recognition a noncompensatory cue? Journal of Behavioral Decision Making, 21, 183-210.
Pachur, T., \& Hertwig, R. (2006). On the psychology of the recognition heuristic: Retrieval primacy as a key determinant of its use. Journal of Experimental Psychology: Learning, Memory, and Cognition, 32, 983-1002.

Pachur, T., Hertwig, R., \& Rieskamp, J. (in press). The mind as an intuitive pollster. In R. Hertwig, U. Hoffrage \& the ABC Research Group (Eds.), Social heuristics that make us smart. New York: Oxford University Press.

Pachur, T., Rieskamp, J., \& Hertwig, R. (2005). The social circle heuristic: Fast and frugal decisions based on small samples. In K. Forbus, D. Gentner, \& T. Regier (Eds.), Proceedings of the 26th annual conference of the Cognitive Science Society (pp. 1077-1082). Mahwah, NJ: Erlbaum.

Pachur, T., Todd, P. M., Gigerenzer, G., Schooler, L. J., \& Goldstein, D. G. (in press). When is ignorance an adaptive tool? In P. M. Todd, G. Gigerenzer, \& the ABC Research Group (Eds.), Ecological rationality: Intelligence in the world. New York: Oxford University Press.

Page, S. E. (2007). The difference. How the power of diversity creates better groups, firms, schools, and societies. Princeton, NJ: Princeton University Press.

Payne, J. W., Bettman, J. R., \& Johnson, E. J. (1993). The adaptive decision maker. New York: Cambridge University Press.

Piattelli-Palmarini, M. (1994). Inevitable illusions: How mistakes of reason rule our minds. New York: John Wiley \& Sons.

Pohl, R. F. (2006). Empirical tests of the recognition heuristic. Journal of Behavioral Decision Making, 19, 251-271.

Price, J. (2008). Parent-child quality time: Does birth order matter? Journal of Human Resources, 43, 240-265.

Rabin, M. (1993). Incorporating fairness into game theory and economics. The American Economic Review, 83, 1281-1302.

Rabin, M. (1998). Psychology and economics. Journal of Economic Literature, 36, 11-46.

Rapoport, A., \& Chammah, A. M. (1965). Prisoner's dilemma: A study in conflict and cooperation. Ann Arbor, MI: University of Michigan Press.

Raz, O., \& Ert, E. (2008). Size counts: The effect of queue length on choice between similar restaurants. In A. Y. Lee \& D. Soman (Eds.), Advances in consumer research, Vol. 
35 (pp. 803-804). Duluth, MN: Association for Consumer Research.

Reimer, T., \& Hoffrage, U. (2006). The ecological rationality of simple group heuristics: Effects of group member strategies on decision accuracy. Theory and Decision, 60, 403-438.

Reimer, T., \& Katsikopoulos, K. V. (2004). The use of recognition in group decision-making. Cognitive Science, 28, 1009-1029.

Richerson, P. J., \& Boyd, R. (2005). Not by genes alone: How culture transformed human evolution. Chicago: University of Chicago Press.

Richter, T., \& Späth, P. (2006). Recognition is used as one cue among others in judgment and decision making. Journal of Experimental Psychology: Learning, Memory, and Cognition, 32, 150-162.

Rieskamp, J., \& Otto, P. E. (2006). SSL: A theory of how people learn to select strategies. Journal of Experimental Psychology: General, 135, 207-236.

Rieskamp, J., \& Todd, P. M. (2006). The evolution of cooperative strategies for asymmetric social interactions. Theory and Decision, 60, 69-111.

Roberts, S., \& Pashler, H. (2000). How persuasive is a good fit? A comment on theory testing. Psychological Review, 107, 358-367.

Rogers, T. B., Kuiper, N. A., \& Kirker, W. S. (1977). Self-reference and the encoding of personal information. Journal of Personality and Social Psychology, 35, 677-688.

Roth, A. E., Prasnikar, V., Okuno-Fujiwara, M., \& Zamir, S. (1991). Bargaining and market behavior in Jerusalem, Ljubljana, Pittsburgh, and Tokyo: An experimental study. American Economic Review, 81, 1068-1095.

Rubinstein, A. (2003). "Economics and psychology?" The case of hyperbolic discounting. International Economic Review, 44, 1207-1216.

Sacks, O. (1995). An anthropologist on Mars. New York: Vintage Books.

Sanfey, A., Rilling, J., Aronson, J., Nystrom, L., \& Cohen, J. (2003). The neural basis of economic decision-making in the ultimatum game. Science, 300, 1755-1758

Scheibehenne, B., \& Bröder, A. (2007). Predicting Wimbeldon 2005 tennis results by mere player name recognition? International Journal of Forecasting, 23, 415-426.

Scheibehenne, B., Miesler, L., \& Todd, P. M. (2007). Fast and frugal food choices: Uncovering individual decision heuristics. Appetite, 49, 578-589.

Schelling, T. C. (1978). Micromotives and macrobehavior. New York: W. W. Norton \& Company.

Schooler, L. J., \& Hertwig, R. (2005). How forgetting aids heuristic inference. Psychological Review, 112, 610-628.

Selten, R. (2001). What is bounded rationality? In G. Gigerenzer \& R. Selten (Eds.), Bounded rationality: The adaptive toolbox (pp. 13-36). Cambridge, MA: MIT Press.

Sen, A. (1993). Internal consistency of choice. Econometrica, 61, 495-521.

Serwe, S., \& Frings, C. (2006). Who will win Wimbledon? The recognition heuristic in predicting sports events. Journal of Behavioral Decision Making, 19, 321-332.

Seymour, B., \& Dolan, R. (2008). Emotion, decision making, and the Amygdala. Neuron, 58, 662-668.

Shiller, R. J. (2005). Irrational exuberance (2nd ed). Princeton, NJ: Princeton University Press.

Sides, A., Osherson, D., Bonini, N., \& Viale, R. (2002). On the reality of the conjunction fallacy. Memory and Cognition, 30, 191-198.

Simon, H. A. (1956). Rational choice and the structure of the environment. Psychological Review, 63, 129-138.

Simon, H. A. (1957). Models of man. New York: Wiley.

Simon, H. A. (1978). Rational decision making in business organizations. In A. Lindbeck (Ed.), From Nobel lectures, economics 1969-1980. Singapore: World Scientific Publishing Co.

Simon, H. A. (1990a). Alternative visions of reality. In P. K. Moser (Ed.), Rationality in action: Contemporary approaches (pp. 189-204). New York: Cambridge University Press.

Simon, H. A. (1990b). Invariants of human behavior. Annual Review of Psychology, 41, 1-19.

Simon, H. A. (1945/1997). Administrative Behavior (4th ed.). New York: Simon \& Schuster (first published in 1945). 
Snook, B., Taylor, P. J., \& Bennel, C. (2004). Geographic profiling: The fast, frugal, and accurate way. Applied Cognitive Psychology, 18, 105-121.

Snook, B., Zito, M., Bennell, C., \& Taylor, P. J. (2005). On the complexity and accuracy of geographic profiling strategies. Journal of Quantitative Criminology, 21, 1-26.

Soll, J. B., \& Larrick, R. P. (2009). Strategies for revising judgment: How (and how well) people use others' opinions. Journal of Experimental Psychology: Learning, Memory and Cognition, 35, 780-805.

Sperber, D. (1994). The modularity of thought and the epidemiology of representations. In L. A. Hirschfeld \& S. A. Gelman (Eds.), Mapping the mind: Domain specificity in cognition and culture (pp. 39-67). Cambridge: Cambridge University Press.

Sterelny, K. (2003). Thought in a hostile world. Oxford, UK: Blackwell.

Stevens, J. R., \& Hauser, M. D. (2004). Why be nice? Psychological constraints on the evolution of cooperation. Trends in Cognitive Sciences, 8, 60-65.

Stigler, G. J. (1981). Economics or ethics? In S. M. McMurrin (Ed.), The Tanner lectures on human values (pp. 143-191). Salt Lake City, UT: University of Utah Press.

Suitor, J. J., Sechrist, J., Plikuhn, M., Pardo, S. T., \& Pillemer, K., (2008). Within-family differences in parent-child relations across the life course. Current Directions in Psychological Science, 17, 334-338.

Sunstein, C. R. (Ed.) (2000). Behavioral law and economics. Cambridge, UK: Cambridge University Press.

Surowiecki, J. (2004). The wisdom of crowds. New York: Doubleday.

Svenson, O. (1981). Are we all less risky and more skillful than our fellow drivers? Acta Psychologica, 47, 143-148.

Sweetser, E. E. (1990). From etymology to pragmatics: Metaphorical and cultural aspects of semantic structure. Cambridge, UK: Cambridge University Press.

Tetlock, P. E. (2003). Thinking the unthinkable: Sacred values and taboo cognitions. Trends in Cognitive Sciences, 7, 320-324.
Todd, P. M., \& Dieckmann, A. (in press). Simple rules for ordering cues in one-reason decision making. In P. M. Todd, G. Gigerenzer \& the ABC Research Group (Eds.), Ecological rationality: Intelligence in the world. New York: Oxford University Press.

Todd, P. M., Gigerenzer, G., \& the ABC Research Group. (in press). Ecological rationality: Intelligence in the world. New York: Oxford University Press.

Todd, P. M., Hertwig, R., \& Hoffrage, U. (2005). Evolutionary cognitive psychology. In D. M. Buss (Ed.), The handbook of evolutionary psychology (pp. 776-802). Hoboken, NJ: John Wiley \& Sons.

Todd, P. M., \& Miller, G. F. (1999). From pride and prejudice to persuasion: Satisficing in mate search. In G. Gigerenzer, P. M. Todd, \& the ABC Research Group (Eds.), Simple heuristics that make us smart (pp. 287-308). New York: Oxford University Press.

Trivers, R. L. (1971). The evolution of reciprocal altruism. Quarterly Review of Biology, $46,35-57$.

Tversky, A., \& Kahneman, D. (1973). Availability: A heuristic for judging frequency and probability. Cognitive Psychology, 5 , 207-232.

Tversky, A. \& Kahneman, D. (1983). Extensional versus intuitive reasoning: The conjunction fallacy in probability judgment. Psychological Review, 90, 293-315.

Tversky A., \& Kahneman, D. (1992). Advances in prospect theory: Cumulative representation of uncertainty. Journal of Risk and Uncertainty, 5, 297-323.

Yaniv, I. (2004). The benefit of additional opinions. Current Directions in Psychological Science, 13, 75-78.

Yaniv, I., \& Milyavsky, M. (2007). Using advice from multiple sources to revise and improve judgments. Organizational Behavior and Human Decision Processes, 103 104-120. 